\title{
Human TCR-MHC coevolution after divergence from mice includes increased nontemplate-encoded CDR3 diversity
}

\author{
Xiaojing Chen, ${ }^{1,2}$ Lucia Poncette, ${ }^{1}$ and Thomas Blankenstein ${ }^{1,2,3}$ \\ ${ }^{1}$ Max-Delbrück-Center for Molecular Medicine, Berlin, Germany \\ ${ }^{2}$ Charité Campus Buch, Institute of Immunology, Berlin, Germany \\ ${ }^{3}$ Berlin Institute of Health, Berlin, Germany
}

For thymic selection and responses to pathogens, T cells interact through their $\boldsymbol{\alpha} \beta$ T cell receptor (TCR) with peptide-major histocompatibility complex (MHC) molecules on antigen-presenting cells. How the diverse TCRs interact with a multitude of MHC molecules is unresolved. It is also unclear how humans generate larger TCR repertoires than mice do. We compared the TCR repertoire of CD4 T cells selected from a single mouse or human MHC class II (MHC II) in mice containing the human TCR gene loci. Human MHC II yielded greater thymic output and a more diverse TCR repertoire. The complementarity determining region 3 (CDR3) length adjusted for different inherent V-segment affinities to MHC II. Humans evolved with greater nontemplate-encoded CDR3 diversity than did mice. Our data, which demonstrate human TCR-MHC coevolution after divergence from rodents, explain the greater T cell diversity in humans and suggest a mechanism for ensuring that any $\mathrm{V}-\mathrm{J}$ gene combination can be selected by a single MHC II.

\section{INTRODUCTION}

A key event in $\alpha \beta$ T cell-mediated interactions is the binding of the TCR to its ligand in the form of short peptides, which are bound to MHC molecules on the surface of APCs. To accommodate the vast amount of antigens presented by various MHC molecules, T cells must generate a diverse $\alpha \beta$ TCR repertoire. $\mathrm{T}$ cells achieve that task by recombining each one of the multiple germline-encoded variable (V), diversity (D), and joining $(\mathrm{J})$ gene segments; nontemplate additions/deletions of nucleotides in the $\mathrm{V}(\mathrm{D}) \mathrm{J}$ junctional region; and random $\alpha \beta$ chain pairing (Davis and Bjorkman, 1988). Each T cell expresses a unique TCR. Upon encountering antigens, TCRs also undergo conformational adjustments, a so-called induced-fit binding, to ensure specific recognition of respective peptide-MHCs (pMHCs; Krogsgaard and Davis, 2005).

An old question is how $\mathrm{T}$ cells, with such TCR diversity (theoretically $\sim 10^{15}$ clonotypes) and TCR plasticity, react almost exclusively in a MHC-restricted fashion and can react to almost any $\mathrm{MHC}$ molecule, considering the great polymorphism of MHC genes ( 15,000 variants in humans; Robinson et al., 2003). Positive selection during T cell development in the thymus imposes self-MHC restriction on $\mathrm{T}$ cells because only $\alpha \beta \mathrm{T}$ cells that bind to self-pMHC complexes with low affinity receive a survival signal (Davis and Bjorkman, 1988; Jameson et al., 1995). Approximately 15\% of thymocytes induce signaling for thymic selection; of which, half are negatively selected, likely because of too great an affinity for self-pMHC and cross-reactivity (Merkenschlager et

Correspondence to Thomas Blankenstein: tblanke@mdc-berlin.de

Abbreviations used: HA, hemagglutinin; MMTV, mouse mammary tumor virus; PCA principle component analysis; $\mathrm{PMHC}$, peptide-MHC; Tcon, conventional CD4 T cell TdT, terminal deoxynucleotidyl transferase; Treg, regulatory T cell. al., 1997; McDonald et al., 2015). The relatively high proportion of MHC-reactive $\mathrm{T}$ cells in the preselection pool $(\sim 5-20 \%)$ or the fact that $\sim 10 \%$ of the peripheral $\mathrm{T}$ cells are MHC alloreactive indicates an intrinsic affinity of TCRs toward MHC (Blackman et al., 1986; Zerrahn et al., 1997; Suchin et al., 2001; Blattman et al., 2002). Namely, the germline-encoded complementarity determining region (CDR) 1 and $\mathrm{CDR} 2$ of the $\mathrm{V} \alpha$ and $\mathrm{V} \beta$ segments are evolutionarily conserved to react with $\mathrm{MHC}$ molecules, which was termed TCR germline bias (Huseby et al., 2005; Marrack et al., 2008; Garcia et al., 2009).

Compelling evidence for this hypothesis resulted from structural and mutational analysis, showing that single amino acid substitutions in a mouseV $\beta$ CDR2, e.g., Tyr48, Tyr50, and Glu54, decreased positive selection in a TCR transgenic mouse model (Dai et al., 2008; Scott-Browne et al., 2009). Furthermore, some V $\beta$ genes of jawed vertebrates (frog, shark, trout, and lizard), which diverged from mammals $\sim 400$ million years ago, share sequences in the CDR 2 region of mouse $V \beta 8.2$ but otherwise exhibit little similarity. T cells with chimeric TCRs, containing such $\mathrm{V} \beta$ genes, e.g., derived from frogs, were positively selected in mice (Scott-Browne et al., 2011). Further evidence is mounting from the growing database of TCRpMHC ternary, crystallographic structures (Rossjohn et al., 2015).With few exceptions (Beringer et al., 2015; Rossjohn et al., 2015), many of the solved TCR-pMHC structures to date have adapted a diagonal docking topology atop the pMHC complex. Namely, the CDR1 and CDR2 domains of TCR $\alpha$

0 2017 Chen et al. This article is distributed under the terms of an Attribution-Noncommercial-Share Alike-No Mirror Sites license for the first six months after the publication date (see http://www.rupress.org Alike-No Mirror Sites license for the first six months after the publication date (see http://www.rupress.org
/terms/). After six months it is available under a Creative Commons License (Attribution-NoncommercialShare Alike 4.0 International license, as described at https://creativecommons.org/licenses/by-nc-sa/4.0/). 
or $\beta$ chains fix over the $\alpha 2$ and $\alpha 1$ helix of MHC class I (MHC I) or $\beta$ and $\alpha$ helix of MHC II, whereas the CDR $3 \alpha$ and the CDR3 $\beta$ are mainly in contact with the presented peptide, respectively (Rossjohn et al., 2015; Adams et al., 2016).

However, not all V gene segments share conserved residues in CDR1 and CDR2. Therefore, it was suggested that each $\mathrm{V}$ segment engages to its cognate $\mathrm{MHC}$ through a menu of structurally coded recognition motifs that have arisen evolutionarily (Feng et al., 2007; Marrack et al., 2008; Garcia et al., 2009), a comprehensive hypothesis, which, however, is difficult to address experimentally. A number of similarly convincing studies, including the demonstration of antibody-like $\mathrm{T}$ cells that developed in coreceptor and MHC-deficient mice and some structural analyses of TCR-pMHC complexes did not support the TCR germline bias for MHC. Hence, it is not generally accepted that TCR and MHC coevolved (Tynan et al., 2005; Gras et al., 2010; Sethi et al., 2011; Tikhonova et al., 2012; Van Laethem et al., 2013; Beringer et al., 2015), which is not surprising, given the complex and flexible interactions that TCR and MHC can undergo.

Structural and mutational analysis of TCR-pMHC complexes depicts only a few of the billions of different possible combinations. Therefore, we wished to address the problem differently, based on several assumptions. We reasoned that thymic selection is the most sensitive readout to detect subtle differences in affinity between a defined MHC molecule and any given TCR. Even though mouse TCRs can be selected on human MHC (Kievits et al., 1987; Ito et al., 1996) and human TCRs can be selected on mouse MHC (Li et al., 2010), we assumed that mouse and human TCR and MHC gene loci further coevolved after their divergence $~ 75$ million years ago (Waterston et al., 2002), resulting in changes in thymic selection of a polyclonal repertoire, depending on whether the TCR-pMHC interaction was specific for inter- or intraspecies. Therefore, we employed mice with a polyclonal human $\alpha \beta$ TCR repertoire, which were deficient for mouse $\alpha \beta$ TCRs and expressed either a single human MHC II (HLA-DRA/HLA-DRB1*0401; HLA-DR4, hereafter) or a single-mouse MHC II gene $\left(\mathrm{I}-\mathrm{A}^{\mathrm{b}}\right)$. TCR deep-sequencing of peripheral CD4 $\mathrm{T}$ cells from both mouse lines revealed distinct differences in their repertoire, compatible with coevolution of TCR and MHC.

\section{RESULTS \\ Human TCR gene loci transgenic mice with mouse or human MHC II gene}

ABabDII and ABabDR 4 mice, which both contain complete human TCR $\alpha$ and TCR $\beta$ gene loci and a single MHC II, mouse I-A ${ }^{\mathrm{b}}$, or human HLA-DR4, were employed in this study. Both strains are deficient for mouse $\alpha \beta$ TCRs. ABabDII mice contain the HLA-A*0201 gene and are deficient for mouse MHC I expression ( $\beta 2 \mathrm{~m}$ - and $\mathrm{D}^{\mathrm{b}}$-deficient), whereas ABabDR 4 mice contain two mouse MHC I genes $\left(\mathrm{K}^{\mathrm{b}}\right.$ and $\left.\mathrm{D}^{\mathrm{b}}\right)$. HLA-A*0201 and HLA-DR 4 are both chimeric molecules allowing mouse CD8 and CD4 coreceptor binding, respectively. The $\alpha 1$ and $\beta 1$ regions of $\mathrm{I}-\mathrm{A}^{\mathrm{b}}$ share 56 and $61 \%$ homology with the human HLA-DR 4 molecule at the amino acid level. Even though $\mathrm{I}_{-} \mathrm{A}^{\mathrm{b}}$ and HLA-DR 4 are not the closest homologues to each other, the TCR repertoire selected by either molecule can be compared, assuming that different MHC II alleles have similar ability to select a diverse repertoire. The cortical and medullary thymic epithelial cells, as well as thymic DCs, which are critical for positive and negative selection of T cells (Klein et al., 2014), expressed comparable levels of MHC II in the two mouse strains (Fig. S1).

\section{Reduced thymic selection by mouse MHC II compared with human MHC II}

ABabDII and ABabDR 4 mice contained comparable levels of double-positive, CD4 single-positive, and CD8 single-positive cells, as well as $\mathrm{CD}^{+}$thymocytes (Fig. 1, A and B). However, ABabDR 4 mice contained more CD5/CD69-positive thymocytes $\left(2.10^{6} \pm 0.5 \times 10^{6}\right.$ cells $)$ than ABabDII mice did $(1.3$ $\times 10^{6} \pm 0.3 \times 10^{6}$ cells $)$, indicating that more $\mathrm{T}$ cells received a positive/negative selection signal (Fig. 1, A and B). However, thymocyte development in ABabDII and ABabDR4 mice was less efficient than it was in C57BL/6 mice (Fig. 1).

In the periphery, ABabDR 4 had more CD4 $\mathrm{T}$ cells than ABabDII mice had, which, however, did not reach statistical significance (Fig. $1 \mathrm{C}$ ). However, conventional CD4 $\mathrm{T}$ cell (Tcon; FoxP3 ${ }^{-} \mathrm{CD} 4^{+} \mathrm{CD}^{+}$) numbers were significantly greater in the periphery in ABabDR 4 compared with ABabDII mice (Fig. 1 D). Regulatory T cell (Treg; Fox$\mathrm{P}^{+} \mathrm{CD}^{+} \mathrm{CD}^{+}$) numbers in both the thymus and spleen in $\mathrm{ABabDII}$ mice were comparable to those in ABabDR 4 mice, but the frequency of Treg within the CD4 T cells was substantially greater in ABabDII (19.9 $\pm 4.4 \%)$ compared with ABabDR 4 mice $(10.8 \pm 4.0 \%$; Fig. $1 \mathrm{D}$ and Fig. S2, A and B).

Similar numbers and frequencies of Treg cells expressed high levels of CD44, a homeostatic proliferation marker for naive $\mathrm{T}$ cells, although greater frequency of Tcon cells in ABabDII mice were CD $44^{\text {hi }}(51.7 \pm 6.1 \%)$ compared with ABabDR 4 mice $(30.0 \pm 15.1 \%$; Fig. $1 \mathrm{D}$ and Fig. S2, A and C). Treg cells and Tcon cells had similar V $\beta$ usages in both ABabDII and ABabDR 4 mice, based on staining with 24 human $\mathrm{V} \beta$ antibodies (Fig. S2 D).

Because ABabDII and ABabDR 4 mice had comparable frequencies of peripheral CD8 T cells, it is unlikely that the different MHC I molecules shaped the development of CD4T cells (Fig. 1 C). Collectively, these data showed that the development of CD4 T cells with human TCRs differed depending on whether they were selected by mouse or human MHC II.

\section{Diverse but nonrandom V-J usage in both mice and humans} We compared the $\alpha \beta$ TCR repertoire of CD $4 \mathrm{~T}$ cells of ABabDII and ABabDR 4 mice by quantitative deep sequencing. The CD8 $\mathrm{T}$ cell repertoires were not sequenced because ABabDR 4 possess two MHC I alleles, whereas ABabDII mice have only one human MHC I. We included similar numbers of naive $\left(\mathrm{CD} 6 \mathrm{~L}^{+} / \mathrm{CD} 45 \mathrm{RO}^{-}\right) \mathrm{CD} 4 \mathrm{~T}$ cells from 

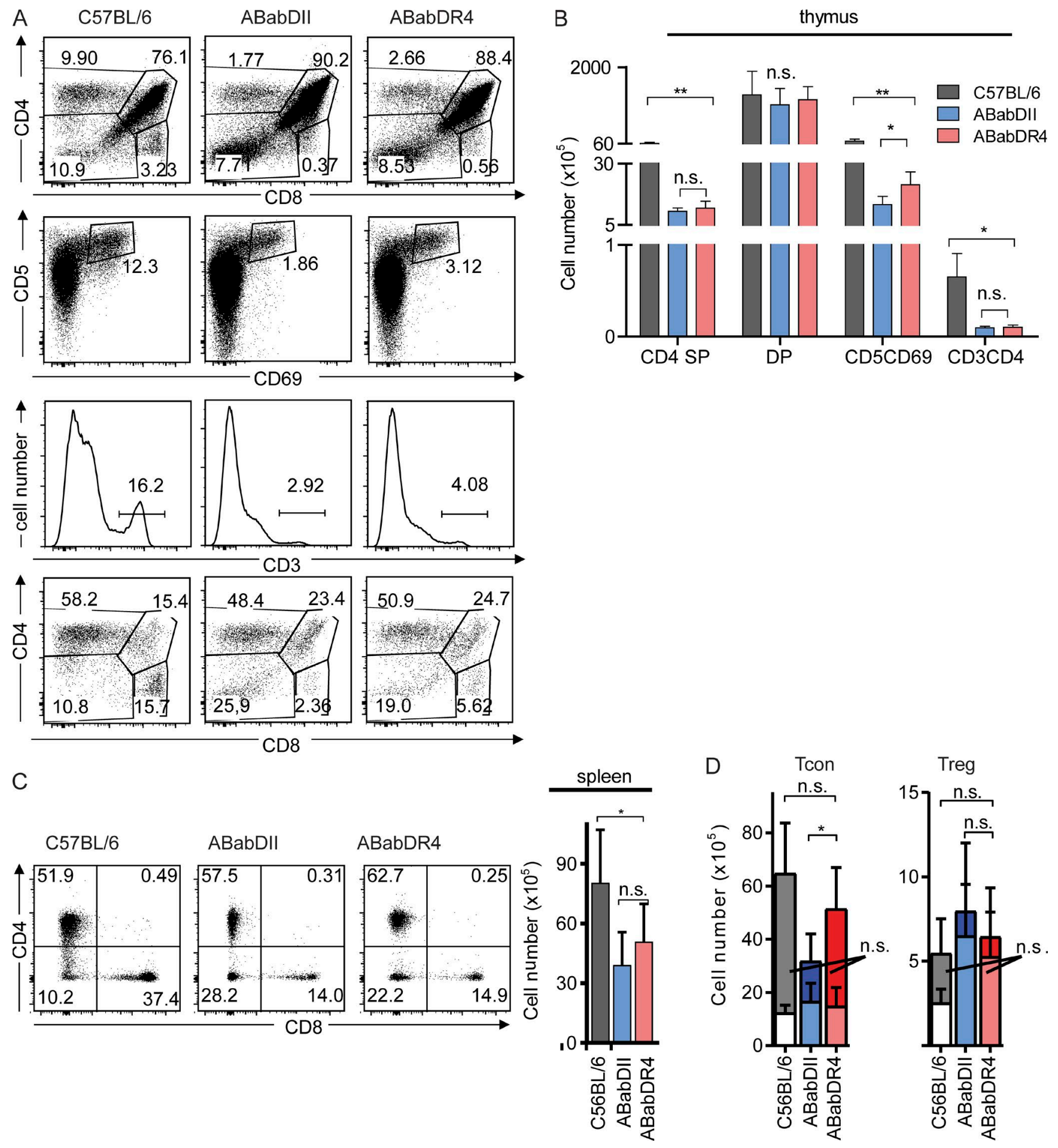

Figure 1. T cell development in C57BL/6, ABabDII, and ABabDR4 mice. (A) Thymocyte staining. First lane, CD4, CD8 double- and single-positive cells; second lane, CD5 and CD69 staining; third lane, CD3 staining, gated on living lymphocytes; and fourth lane, CD4 and CD8 double- and single-positive cells gated on CD3 ${ }^{+}$ cells. One representative FACS plot from each of C57BL/6 $(n=3)$, ABabDII $(n=6)$, and ABabDR4 $(n=6)$ mice. Percentage of the gated cells for the whole population is indicated inside or above the gates. (B) Numbers of CD4 single-positive, $C D 5^{+} \mathrm{CD} 69^{+}, \mathrm{CD} 4 \mathrm{CD} 8$ double-positive, and $\mathrm{CD} 3^{+} \mathrm{CD} 4^{+}$thymocytes. (C, left) Representative FACS plots of $\mathrm{CD} 4$ and $\mathrm{CD} 8$ staining from splenocytes, gated on $\mathrm{CD} 3^{+}$living lymphocytes. (C, right) Absolute numbers of CD4 T cells from spleen of C57BL/6, $\mathrm{ABabDII}$, and ABabDR4 mice. The percentage of positive cells is indicated in both $A$ and $C$. (D) Tcon (left) and Treg (right) cell numbers from spleen. Bars with lighter color indicate the CD44 portion of cells from each subgroup. Summarized data (B, C, and D) from C57BL/6 $(n=3)$, ABabDII $(n=6)$, and ABabDR4 $(n=6)$ mice, shown as means \pm SD. ${ }^{*}, 0.001 \leq \mathrm{P}<0.05 ;{ }^{*}, 0.05 \leq \mathrm{P}<0.1 ;$ n.S., not significant (Mann-Whitney test, two-tailed). In addition, Fig. S2 shows FoxP3 thymic and spleen staining. 
three human donors as a case of TCR selection on multiple MHC II alleles. All CD4 T cells were isolated by FACS sort with purities $>97 \%$. We wish to point out, however, that certain parameters, such as $\mathrm{V}(\mathrm{D}) \mathrm{J}$ usage frequency or CDR3 length, but not repertoire diversity, can be compared between the mice and humans because humans contain a set of six different MHC II alleles by which the $\mathrm{T}$ cells were selected. Genomic DNA from $\sim 2.5 \times 10^{5}$ purified CD4 T cells from ABabDII and ABabDR 4 mice and $\sim 1.8 \times 10^{5}$ from human were submitted for sequencing. Between $0.6 \times 10^{7}$ and $1.6 \times$ $10^{7}$ valid reads were obtained (Table 1 ).

We analyzed $\mathrm{V}$ and $\mathrm{J}$ gene usages from both in-frame and out-of-frame TCRs, where the out-of-frame TCRs approximated the preselection pool (Zvyagin et al., 2014). Even though many $\mathrm{T}$ cells with functional TCR rearrangement are not positively selected and, thus, are part of the preselection pool (McDonald et al., 2015), the out-of-frame TCRs in T cells selected by their second functional TCR represents an unbiased estimate of $\mathrm{V}-\mathrm{J}$ usage frequency. Both, the $\mathrm{V} \alpha$ and $\mathrm{V} \beta$ gene usage in the preselection repertoire did not differ between the two mouse groups because ABabDII and ABabDR 4 mice shared the same TCR transgene loci and employed the same TCR recombination enzymes for rearrangement (i.e., RAG proteins).

Most $\mathrm{V} \alpha$ and $\mathrm{V} \beta$ genes were found to be rearranged, except for TRBV5-1, TRBV6-1, and TRAV1, which were previously reported to be missing or not expressed in the $A B a b$ transgenic mice (Fig. 2, A and B; Li et al., 2010). Humans showed a similar out-of-frame $\mathrm{V}$ gene usage. However, some $\mathrm{V} \alpha$ and $\mathrm{V} \beta$ genes were either more frequently (e.g., TRAV16, TRAV39, TRBV23-1, TRBV25-1, TRBV27, TRBV28) or less frequently (e.g., some of the most $5^{\prime}$ located $V \alpha$ genes, TRBV9, TRBV10-1, TRBV6-5, TRBV19) used in the two mouse lines compared with humans. The reason for these differences is not clear but could be related, in some cases, to polymorphisms. For example, in the promoter region of TRAV39, a deletion of five nucleotides (TTTTC; available from GenBank under accession no. NC_000014, positions 22 and 125-22,130) was detected in the mouse samples, compared with the TRAV39 gene in the three human donors. A similar polymorphism (TTTTC deletion) has been observed in the CD4 promoter, which was associated with lower promoter activity (Kristiansen et al., 2004).

Both $\mathrm{V} \alpha$ and $\beta \beta$ gene usage was nonrandom $(\mathrm{P}<0.0001$, $\chi^{2}$ test: actual frequencies to the random gene frequency usage; Fig. 2). The preference for $\operatorname{V} \alpha$ and $V \beta$ gene usage appeared to be different. $V \alpha$ genes that were closer to the $5^{\prime}$ region of the gene locus were underrepresented. $\mathrm{V} \beta$ genes located in the $5^{\prime}$ and $3^{\prime}$ region were preferentially rearranged similarly in mice and humans (i.e., TRBV12-3/4, TRBV21-1, and TRBV27; Fig. 2 B). J $\alpha$ and $\mathrm{J} \beta$ usage was also nonrandom and similar between the transgenic mice and humans (Fig. 2, C and D), although the four J $\alpha$ segments located closest to the $5^{\prime}$ end were used more frequently in mice than in humans.

Table 1. In-frame and out-of-frame TCR $\alpha / \beta$ diversity

\begin{tabular}{|c|c|c|c|c|c|c|c|}
\hline TCR & Source & $\begin{array}{l}\text { In-frame nt } \\
\text { clonotypes }\end{array}$ & $\begin{array}{l}\text { In-frame amino acid } \\
\text { clonotypes }\end{array}$ & $\begin{array}{l}\text { In-frame amino acid } \\
\text { clonotypes (\%) }\end{array}$ & $\begin{array}{l}\text { Out-of-frame } \\
\text { clonotypes }\end{array}$ & $\begin{array}{l}\text { Out-of-frame clono- } \\
\text { types (\%) }\end{array}$ & Summary read \\
\hline \multirow[t]{13}{*}{ TCR $\alpha$} & \multirow[t]{5}{*}{ ABabDII } & $8 \times 10^{4}$ & $6.8 \times 10^{4}$ & 0.70 & $10 \times 10^{4}$ & 0.54 & $1.5 \times 10^{7}$ \\
\hline & & $9 \times 10^{4}$ & $7.6 \times 10^{4}$ & 0.68 & $12 \times 10^{4}$ & 0.54 & $1.0 \times 10^{7}$ \\
\hline & & $9 \times 10^{4}$ & $7.6 \times 10^{4}$ & 0.68 & $13 \times 10^{4}$ & 0.56 & $1.3 \times 10^{7}$ \\
\hline & & $10 \times 10^{4}$ & $8.2 \times 10^{4}$ & 0.68 & $14 \times 10^{4}$ & 0.56 & $1.2 \times 10^{7}$ \\
\hline & & $8 \times 10^{4}$ & $7.0 \times 10^{4}$ & 0.70 & $11 \times 10^{4}$ & 0.56 & $1.1 \times 10^{7}$ \\
\hline & \multirow[t]{5}{*}{ ABabDR4 } & $14 \times 10^{4}$ & $10.8 \times 10^{4}$ & 0.65 & $20 \times 10^{4}$ & 0.58 & $1.6 \times 10^{7}$ \\
\hline & & $12 \times 10^{4}$ & $9.5 \times 10^{4}$ & 0.66 & $1.8 \times 10^{4}$ & 0.59 & $1.0 \times 10^{7}$ \\
\hline & & $11 \times 10^{4}$ & $8.7 \times 10^{4}$ & 0.68 & $1.7 \times 10^{4}$ & 0.59 & $1.0 \times 10^{7}$ \\
\hline & & $13 \times 10^{4}$ & $10.7 \times 10^{4}$ & 0.65 & $20 \times 10^{4}$ & 0.59 & $1.4 \times 10^{7}$ \\
\hline & & $13 \times 10^{4}$ & $10.4 \times 10^{4}$ & 0.65 & $18 \times 10^{4}$ & 0.56 & $1.3 \times 10^{7}$ \\
\hline & \multirow[t]{3}{*}{ Humans } & $21 \times 10^{4}$ & $18.6 \times 10^{4}$ & 0.77 & $21 \times 10^{4}$ & 0.49 & $1.3 \times 10^{7}$ \\
\hline & & $18 \times 10^{4}$ & $15.2 \times 10^{4}$ & 0.78 & $15 \times 10^{4}$ & 0.45 & $1.0 \times 10^{7}$ \\
\hline & & $12 \times 10^{4}$ & $10.4 \times 10^{4}$ & 0.80 & $8.6 \times 10^{4}$ & 0.41 & $1.0 \times 10^{7}$ \\
\hline \multirow[t]{13}{*}{ TCR $\beta$} & \multirow[t]{5}{*}{ ABabDII } & $10 \times 10^{4}$ & $9.0 \times 10^{4}$ & 0.78 & $1.1 \times 10^{4}$ & 0.50 & $0.7 \times 10^{7}$ \\
\hline & & $8 \times 10^{4}$ & $7.5 \times 10^{4}$ & 0.79 & $0.9 \times 10^{4}$ & 0.49 & $0.6 \times 10^{7}$ \\
\hline & & $9 \times 10^{4}$ & $8.4 \times 10^{4}$ & 0.79 & $0.9 \times 10^{4}$ & 0.48 & $0.7 \times 10^{7}$ \\
\hline & & $11 \times 10^{4}$ & $10.2 \times 10^{4}$ & 0.79 & $1.0 \times 10^{4}$ & 0.46 & $0.7 \times 10^{7}$ \\
\hline & & $10 \times 10^{4}$ & $8.7 \times 10^{4}$ & 0.79 & $1.0 \times 10^{4}$ & 0.50 & $0.7 \times 10^{7}$ \\
\hline & \multirow[t]{5}{*}{ ABabDR4 } & $12 \times 10^{4}$ & $11.0 \times 10^{4}$ & 0.77 & $1.4 \times 10^{4}$ & 0.51 & $0.8 \times 10^{7}$ \\
\hline & & $12 \times 10^{4}$ & $11.1 \times 10^{4}$ & 0.77 & $1.4 \times 10^{4}$ & 0.51 & $0.9 \times 10^{7}$ \\
\hline & & $13 \times 10^{4}$ & $11.7 \times 10^{4}$ & 0.76 & $1.5 \times 10^{4}$ & 0.51 & $0.9 \times 10^{7}$ \\
\hline & & $16 \times 10^{4}$ & $14.1 \times 10^{4}$ & 0.76 & $1.8 \times 10^{4}$ & 0.51 & $0.9 \times 10^{7}$ \\
\hline & & $17 \times 10^{4}$ & $15.0 \times 10^{4}$ & 0.75 & $1.9 \times 10^{4}$ & 0.50 & $1.0 \times 10^{7}$ \\
\hline & \multirow[t]{3}{*}{ Humans } & $13 \times 10^{4}$ & $12.3 \times 10^{4}$ & 0.92 & $3 \times 10^{4}$ & 0.17 & $0.6 \times 10^{7}$ \\
\hline & & $14 \times 10^{4}$ & $13.2 \times 10^{4}$ & 0.91 & $2 \times 10^{4}$ & 0.14 & $0.7 \times 10^{7}$ \\
\hline & & $10 \times 10^{4}$ & $9.6 \times 10^{4}$ & 0.92 & $2 \times 10^{4}$ & 0.18 & $0.7 \times 10^{7}$ \\
\hline
\end{tabular}

nt, nucleotide. 


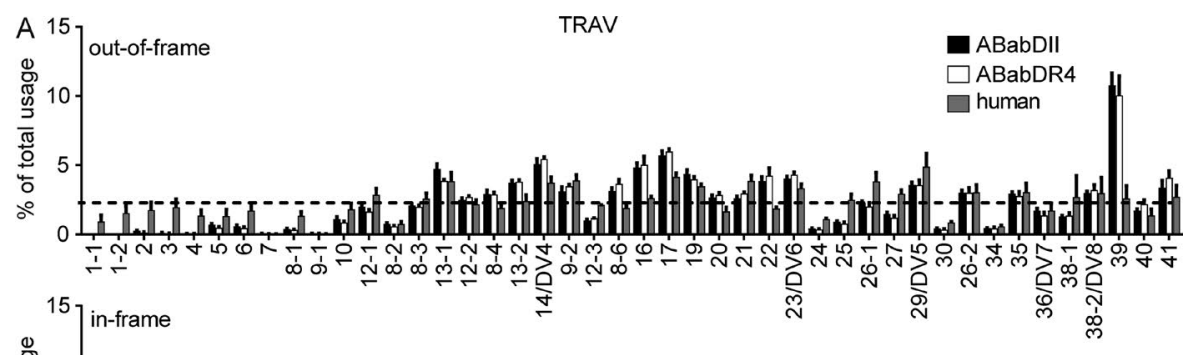

Figure 2. $\quad \mathrm{V}$ and $\mathrm{J}$ gene usage frequencies of out-of-frame and in-frame TCR clonotypes. Frequencies include TCR $\alpha(A)$ and $\operatorname{TCR} \beta$ (B) V gene or TCR $\alpha$ (C) and TCR $\beta$ (D) J gene usage of unique TCR clonotypes in CD4 T cells of ABabDll mice $(n=5)$, ABabDR4 $(n=$ 5) mice and human donors $(n=3)$. The gene segments were arranged on the $x$ axis according to their position on the human chromosome from $5^{\prime}$ to $3^{\prime}$. TRAV18 usage was not detected, most likely because of PCR bias, and was excluded from the graph. Dashed line indicates frequency for random $V$ gene usage (TRAV, 2.3\%; TRBV, 2.1\%). All data are shown as means $\pm S D .{ }^{*}, V$ genes whose expression is missing in $A B a b$ transgenic mice.
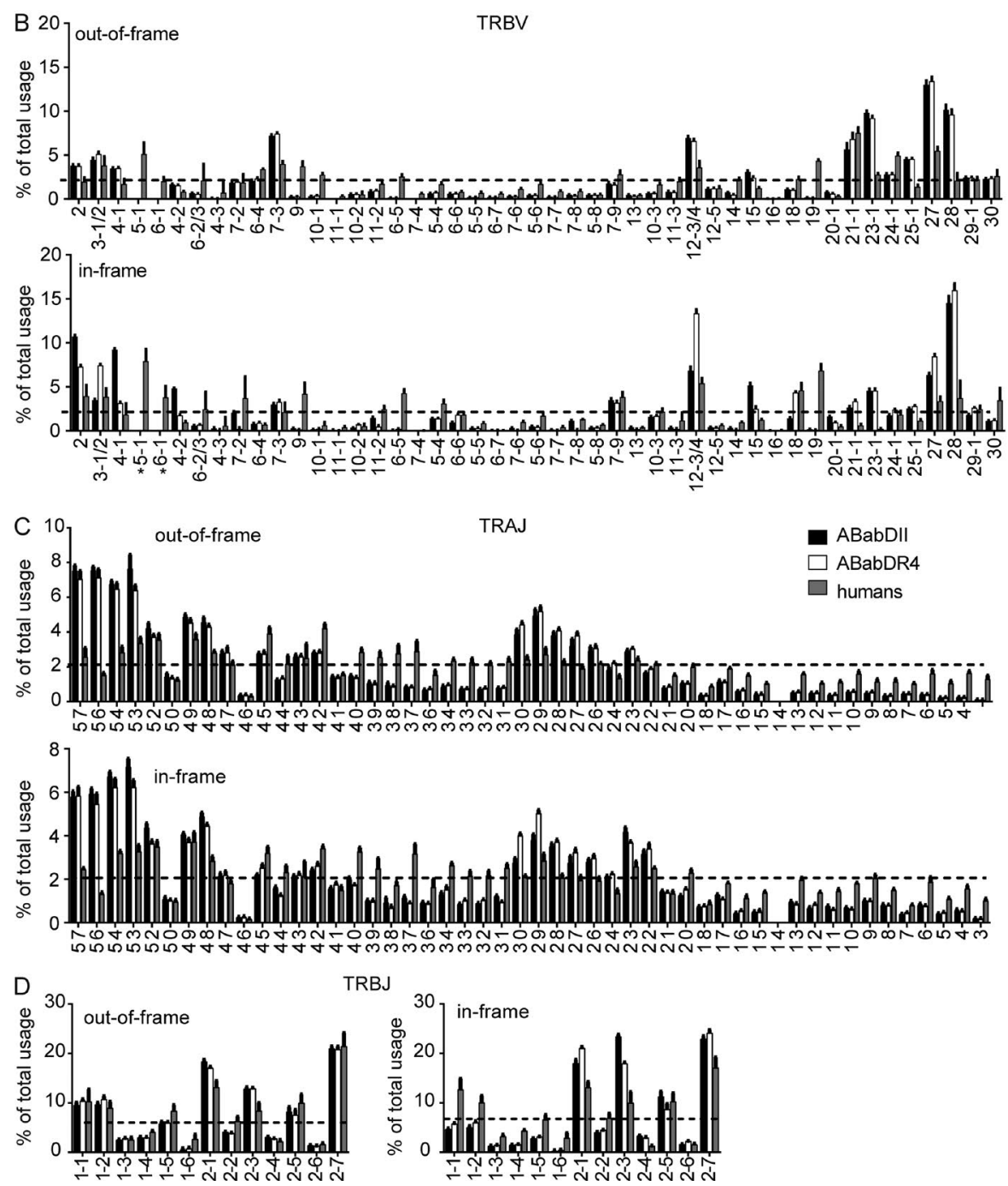

Most $\mathrm{V} \alpha-\mathrm{J} \alpha$ and $\mathrm{V} \beta-\mathrm{J} \beta$ gene combinations were detected in both the in-frame and the out-of-frame repertoire (Fig. 3). In general, the postselection repertoire for both the $\alpha$ and the $\beta$ chains mirrored the usage pattern of the preselection repertoire similarly in ABabDII and ABabDR 4 mice (Figs. 2 and 3). However, we also observed changes in the pre- versus postselection repertoire for some $\mathrm{V}$ genes and $\mathrm{V}-\mathrm{J}$ pairing (see I-A ${ }^{\mathrm{b}}$ and HLA-DR 4 have distinct imprint in TCR selection). 


\section{Larger CD4 T cell repertoire in ABabDR4 compared with ABabDII mice}

ABabDII mice were able to select a diverse human TCR repertoire with a mean of $7.5 \times 10^{4} \pm 0.60 \times 10^{4}$ in-frame $\operatorname{TCR} \alpha$ and $8.8 \times 10^{4} \pm 0.97 \times 10^{4} \mathrm{TCR} \beta$ amino acid clonotypes from the CD4 $\mathrm{T}$ cells submitted for sequencing (Fig. $4 \mathrm{~A}$ and Table 1). Thus, I-A $\mathrm{A}^{\mathrm{b}}$ molecules can positively select all human $\mathrm{V} \alpha-\mathrm{J} \alpha$ and $\mathrm{V} \beta-\mathrm{J} \beta$ combinations (Fig. 3). However, HLA-DR 4 selected significantly more functional TCR $\alpha$ and TCR $\beta$ clonotypes compared with $\mathrm{I}-\mathrm{A}^{\mathrm{b}}$ from the same number of T cells $\left(10.0 \times 10^{4} \pm 0.87 \times 10^{4}\right.$ and $12.6 \times$ $10^{4} \pm 1.83 \times 10^{4}$ TCR $\alpha$ and TCR $\beta$ clonotypes, respectively; Fig. $4 \mathrm{~A}$ and Table 1). Humans had the most TCR $\alpha$ clonotypes $\left(14.8 \times 10^{4} \pm 4.08 \times 10^{4}\right)$, likely because of the effect of positive selection by multiple MHC II molecules but, surprisingly, similar numbers of TCR $\beta$ clonotypes $\left(11.7 \times 10^{4} \pm\right.$ $1.89 \times 10^{4}$ ) compared with ABabDR 4 mice.

There were more medium-to-large and fewer rareto-small TCR $\alpha$ and TCR $\beta$ clonotypes in ABabDII mice than in ABabDR 4 mice (Fig. 4, B and C). Most TCR $\alpha$ and TCR $\beta$ clonotypes were rare to small in the two younger human donors. The third donor, aged $60 \mathrm{yr}$, had some hyperexpanded TCR clones and was not included in the clone-size comparison. In general, ABabDR 4 mice had a more homogenous $\operatorname{TCR} \alpha$ and TCR $\beta$ distributions than ABabDII mice had (a mean inequality score of $0.65 \pm 0.01$ vs. $0.70 \pm 0.03$ for $\mathrm{TCR} \alpha$ and $0.57 \pm 0.07$ vs. $0.66 \pm 0.05$ for TCR $\beta$; Fig. $4 \mathrm{D})$. Two of the three human donors had the lowest inequality scores of all three groups.

Because only $\sim 0.5 \%$ of the total CD $4 \mathrm{~T}$ cell repertoire from each mouse was sequenced, we applied a computational approach to determine the total TCR repertoire in CD4 T cells from the mice and humans. A lower-bound estimation on the TCR repertoire size was calculated with the acquired number of productive TCR sequences and the number of their templates detected in the sequencing samples using iCHAO1 estimator (Chiu et al., 2014). HLA-DR4 selected significantly more functional TCR $\alpha$ and TCR $\beta$ clonotypes $\left(3.7 \times 10^{5} \pm 0.4 \times 10^{5}\right.$ and $6.9 \times 10^{5} \pm 0.6 \times 10^{5} \mathrm{TCR} \alpha$ and TCR $\beta$ clonotypes, respectively) compared with I-A $\left(2.4 \times 10^{5} \pm 0.3 \times 10^{5} \mathrm{TCR} \alpha\right.$ and $3.5 \times 10^{5} \pm 0.2 \times 10^{5}$ TCR $\beta$ clonotypes; Fig. 4 E). Humans had the most of both $\operatorname{TCR} \alpha\left(7.2 \times 10^{5} \pm 1.10^{5}\right)$ and $\beta$ clonotypes $\left(16.2 \times 10^{5} \pm\right.$ $\left.2.2 \times 10^{5}\right)$, likely because of the effect of positive selection by multiple MHC II molecules.

Endogenous superantigens, such as the mouse mammary tumor virus (MMTV) superantigens, could alter CD4 T cell selection, e.g., deletion of $\mathrm{T}$ cells with certain $\mathrm{V} \beta$ segments, as observed in HLA-DR4 transgenic mice with a mouse TCR repertoire (Ito et al., 1996). We co-cultured purified CellTrace-labeled CD4 T cells from C57BL/6, ABabDII, ABabDR 4 and DR 4 mice with purified CD19 ${ }^{+}$cells from ABabDII,ABabDR 4 or DR 4 mice for $84 \mathrm{~h}$. Compatible with superantigen recognition, C57BL/6 CD4 T cells responded to stimulation with $\mathrm{B}$ cells from $\mathrm{DR} 4$ and ABabDR 4 mice, however, ABabDII and ABabDR 4 mice, both expressing the human TCR repertoire, did not proliferate to the $\mathrm{B}$ cells of any mouse line (Fig. S3). Thus, we assume that human TCRs, unlike mouse TCRs, only weakly (or not at all) interact with MMTV and conclude that endogenous mouse superantigens did not obscure our results.

\section{I-A $\mathrm{A}^{\mathrm{b}}$ and HLA-DR4 have distinct imprint in TCR selection}

In general, after thymic selection the usage pattern remained similar for both $\mathrm{V} \alpha$ and $\mathrm{V} \beta$ to what it was before selection. However, we also observed changes for some $\mathrm{V}$ genes. For example, TRBV4-1 was strongly preferred by I-A ${ }^{\mathrm{b}}$, but not HLA-DR 4, molecules (Fig. 2). Interestingly, TRBV4-1 is evolutionarily related to a mouse $\operatorname{TCR} \beta$ chain $(V \beta 8.2)$ in the CDR2 region (Scott-Browne et al., 2011). Similarly, TRAV13-1 and TRBV2 were preferentially selected by $\mathrm{I}-\mathrm{A}^{\mathrm{b}}$ molecules. Conversely, some $\mathrm{V}$ genes were preferentially selected by HLA-DR 4 but not $\mathrm{I}^{-A^{\mathrm{b}}}$ molecules, i.e., TRBV3-1/2 and TRBV12-3/4.

To analyze the $\mathrm{V}$ gene usage pattern more globally, an unsupervised method, principle component analysis (PCA), was performed on the $\mathrm{V}$ gene usage profiles of the three groups. PCA separated the human samples on the dominant axis (PC1) but did not do so for the two mouse groups for both in-frame and out-of-frame TCRs, which was also reflected by their closed Euclidean distance (V $\alpha$ : 3.0 and $V \beta$ : 2.3; Fig. 5, A-C). Before selection, the only variable among the three groups may have been solely species difference. Only after thymic selection did ABabDII and ABabDR4 mice and humans separate from each other and cluster on the PC2 axis, suggesting that different MHC II and number of MHC II molecules influenced the $\mathrm{V}$ gene usage and similarly for $\mathrm{V} \alpha$ (Fig. $5 \mathrm{~A}$ ) and $\mathrm{V} \beta$ genes (Fig. 5 B). Indeed, in-frame $\mathrm{V}$ gene usage was rather similar within groups (ED score $\sim 1-2$ ) but significantly different between groups (Fig. 5 C). Based on that observation, we grouped the $\mathrm{V}$ genes whose usage frequency changed significantly compared with out-of-frame TCR for the two mouse strains into "overrepresented," "unchanged," and "underrepresented" (Fig. 6 A). The same distribution pattern and clustering of the three groups in the post- versus preselection repertoire was observed for $\mathrm{V} \alpha-\mathrm{J} \alpha$ and V $\beta-\mathrm{J} \beta$ combinatorial events (Fig. 5, D and E) and, surprisingly, also for J $\alpha$ and $J \beta$ usage frequency (Fig. S4).

A skewed V-J pairing was observed for functional TCR $\alpha$ and $\beta$ chains compared with the preselection pool (Fig. 3, A and B). ABabDII and ABabDR4 had almost the same out-of-frame V-J pairing patterns, and the TRAV131-TRAJ-54/53 and TRBV28-TRBJ2-3/7 were the most prominently selected in both strains. Despite those similarities, the two MHC II molecules also had their own features, e.g., TRBV12-3/4-TRBJ2-1 was the second most selected in ABabDR 4 mice, whereas TRBV2-TRBJ2-7 was the one in ABabDII mice (Fig. 3 B). The distinctive patterns of $\mathrm{V}-\mathrm{J}$ pairing between the two mouse strains, which are imposed by mouse or human MHC II, could also be seen in the PCA 


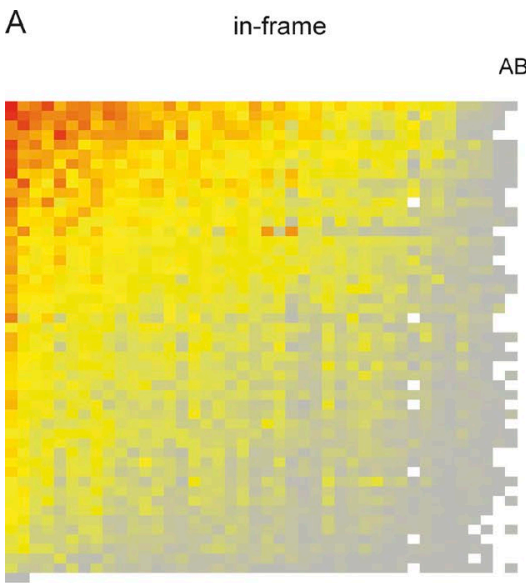

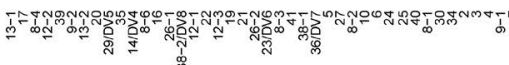

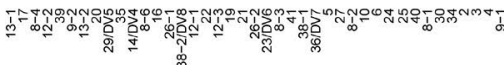

舀
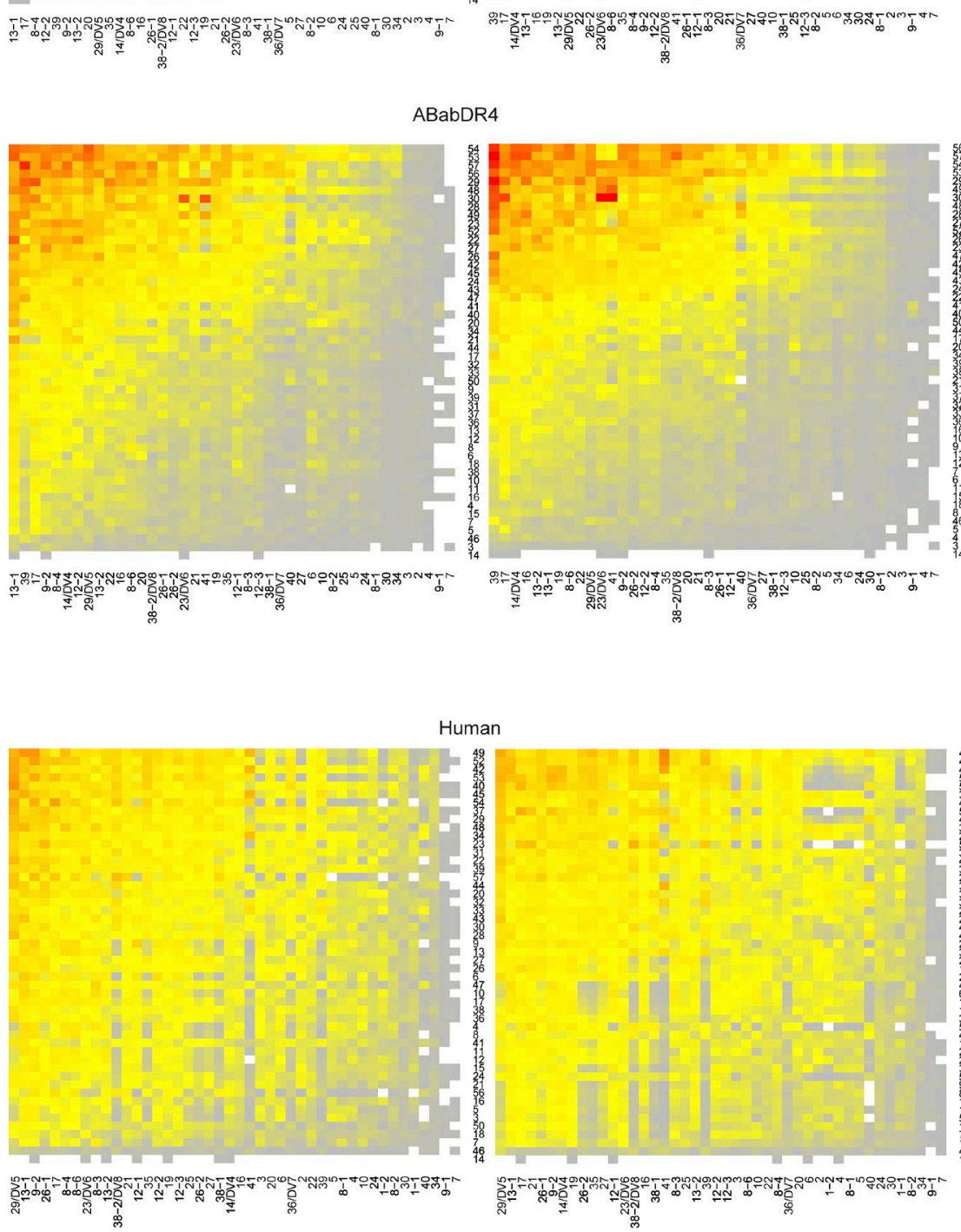

Human
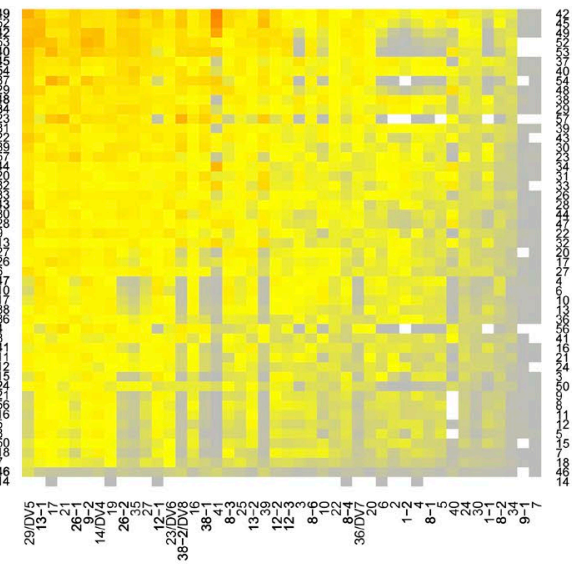

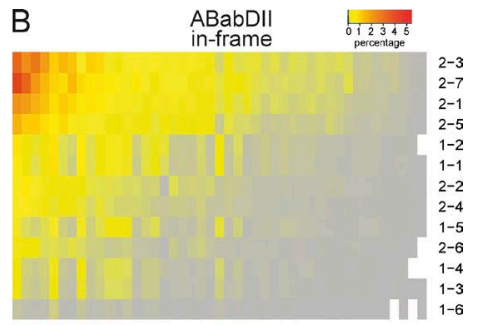

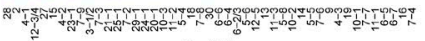

out-of-frame

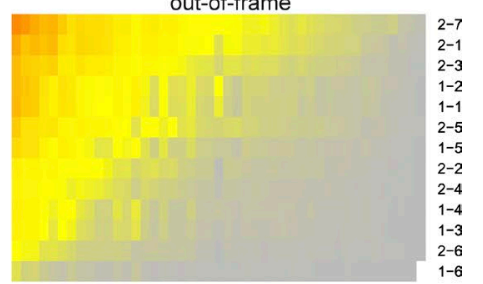

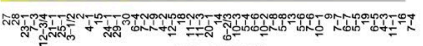

ABabDR4
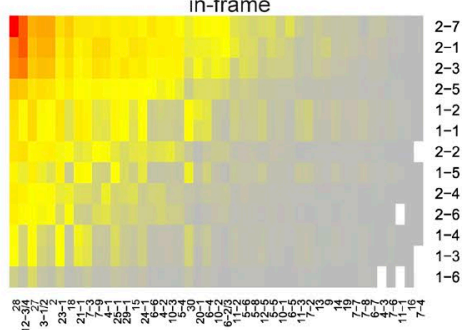

out-of-frame
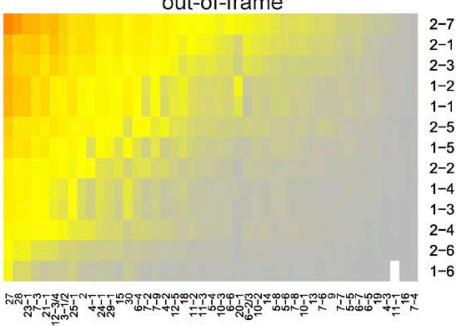

Human

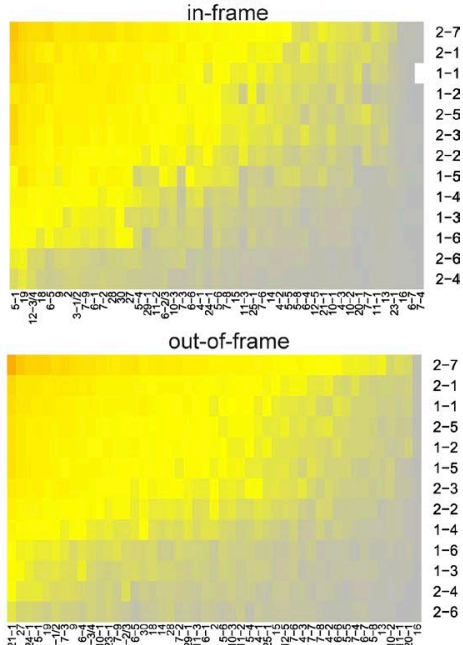

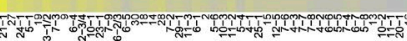

Figure 3. Mean frequencies of V-J pairing of TCR clonotypes. Frequencies include TCR $\alpha$ (A) and TCR $\beta$ (B) V-J pairing of unique TCR clonotypes in ABabDII mice $(n=5)$, ABabDR4 $(n=5)$ mice, and human donors $(n=3)$. The heat maps were arranged by frequency from greatest (red) to the least (gray; top $\rightarrow$ bottom, J segments; left $\rightarrow$ right, V segments). (Left) In-frame; (Right) Out-of-frame. TRAV1, TRBV5-1, and TRBV6-1 were excluded from the analysis for ABabDII and ABabDR4 mice; TRAV18 was excluded for all three groups. 

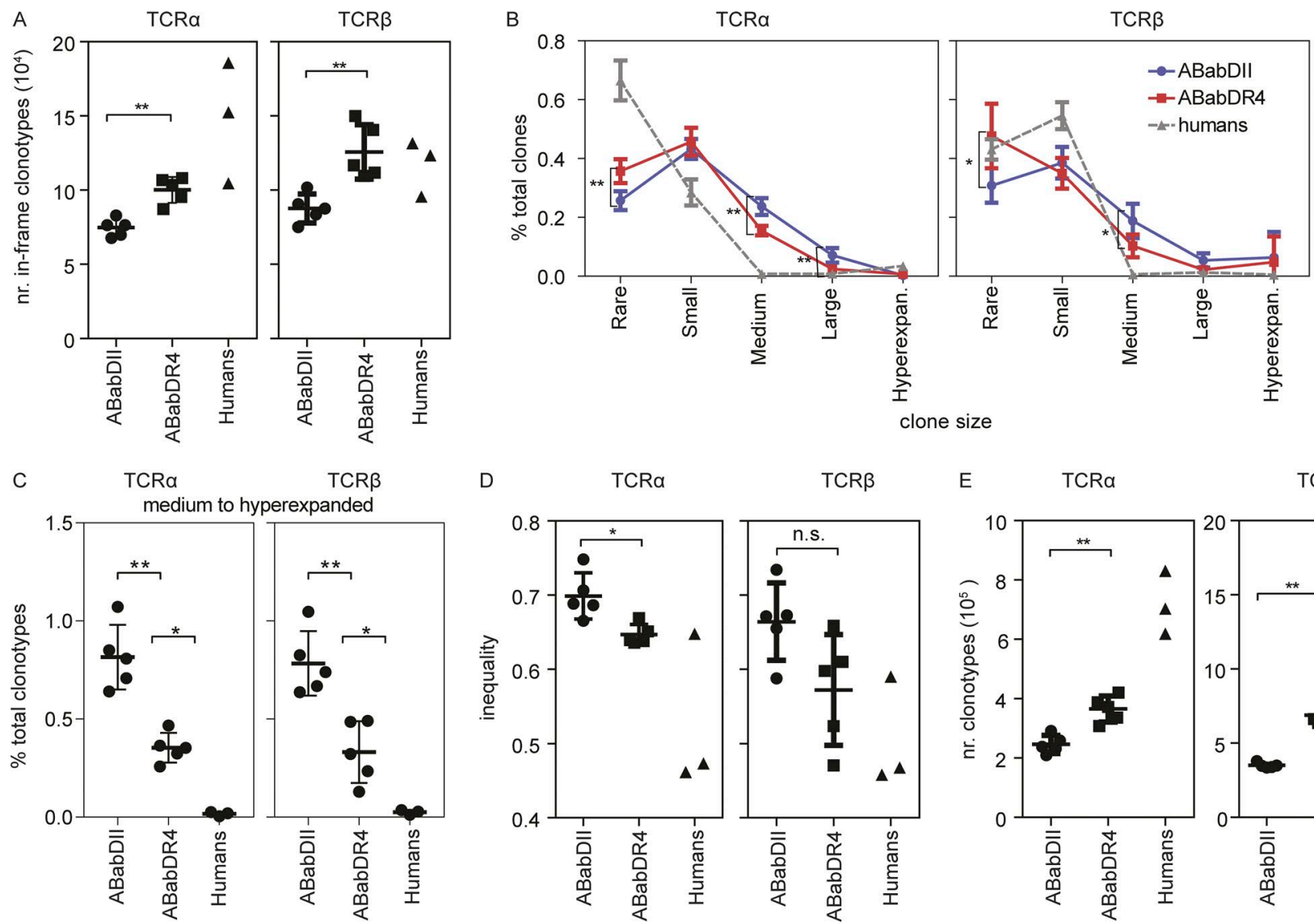

D
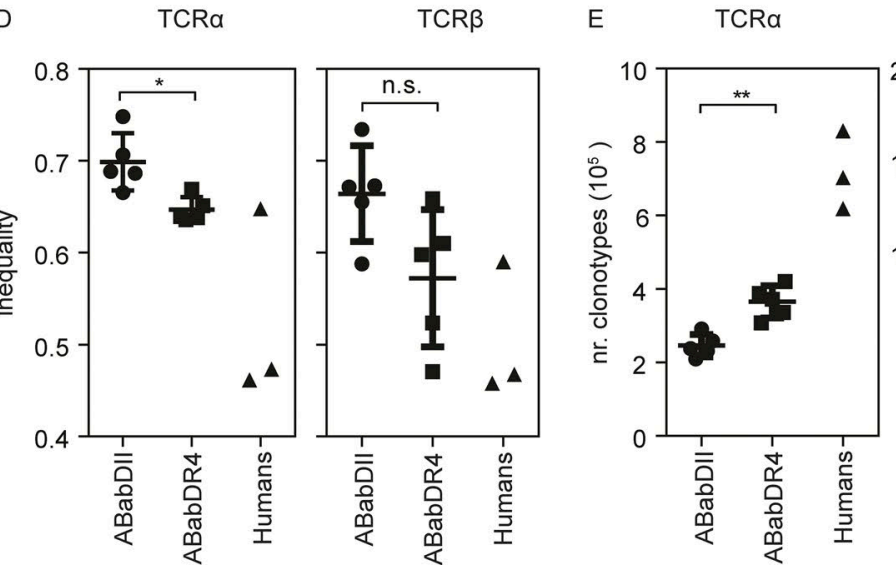

TCR $\beta$

Figure 4. Comparison of TCR $\alpha$ and TCR $\beta$ repertoire among ABabDIl mice, ABabDR4 mice, and human donors. (A) Absolute numbers of unique TCR amino acid clonotypes within $2.5 \times 10^{5}$ mouse or $1.8 \times 10^{5}$ human CD4 T cells. (B) Distribution of TCR amino acid clonotypes of different sizes: rare, $0<x$ $\leq 0.001 \%$; small, $0.001 \%<x \leq 0.01 \%$; mediumm $0.01 \%<x \leq 0.1 \%$; large, $0.1 \%<x<1 \%$; hyperexpanded (hyperexpan.), 1\%<x<10\%. Human donor 3 was omitted from this analysis. Mann-Whitney test was used to compare clonotype sizes between ABabDII and ABabDR4 mice. (C) Percentage of medium to hyperexpanded TCR amino acid clonotypes of the total clonotypes. (D) Gini index indicating the equality of distribution of TCR $\alpha$ and TCR $\beta$ clonotypes (inequality). (E) Numbers of unique TCR $\alpha$ and TCR $\beta$ calculated using the iCHA01 estimator. Data are from ABabDII $(n=5)$; ABabDR4 $(n=5)$ mice, and humans ( $n=2$ for $\mathrm{B} ; n=3$ for $\mathrm{A}, \mathrm{C}$, and D). Mann-Whitney test (two-tailed) was used to compare values between ABabDII and ABabDR4 mice. ${ }^{* *}, 0.001 \leq \mathrm{P}<0.05$; ${ }^{*}, 0.05 \leq P<0.1$; n.s., not significant (Mann-Whitney test). Data from ABabDll and ABabDR4 mice are shown as means $\pm S D$. Means and SD for humans are not depicted. In addition, Table 1 provides a summary of sequencing data and Fig. S2 provides further Treg and Tcon analysis.

analysis (Fig. 5, D and E) and, by comparison, in their Euclidean distance (Fig. 5 F).

\section{HLA-DR4 selects a longer TCR $\beta$ CDR3 compared with I-A}

The $\mathrm{V}(\mathrm{D}) \mathrm{J}$ junctional region (CDR3) generates most diversity within the TCRs and is the major region for antigen contact and recognition. ABabDII and ABabDR 4 mice showed rather similar mean $\operatorname{TCR} \alpha \operatorname{CDR} 3$ length ( $42 \mathrm{bp})$ in the preselection as well as the postselection pool (Figs. 6 $\mathrm{B}$ and $7 \mathrm{~A}$ ). After selection, the CDR3 length distribution narrowed, but $\mathrm{ABabDR} 4$ mice contained a wider range of CDR3 length than ABabDII did. The TCR $\alpha$ CDR3 length distribution in humans was quite similar to that in the mice, yet slightly broader before or after selection (Fig. 7 A).

The TCR $\beta$ CDR 3 length distribution also did not differ in the preselection pool between the two mouse strains; however, humans generated, on average, longer and broader CDR3 region (Fig. 7, B and C). After selection, the CDR3 length distribution narrowed as seen for TCR $\alpha$. The peak of CDR3 length remained the same in ABabDR 4 mice postselection (42 bp), approaching that observed in humans, but decreased in ABabDII mice to 39 bp (Fig. 7, B and C). Most TCR $\beta$ chains selected by HLA-DR 4 molecules had, on average, one amino acid longer CDR 3 compared with those selected by I-A ${ }^{b}$ molecules (Fig. 7, B and C). On average, CDR3 was longer in humans, compared with the two mouse strains in both the pre- and postselection repertoire, which was more apparent for the TCR $\beta$ chain, likely because of two recombinatorial events (V-D-J; Fig. 7 C).

To determine whether the human MHCII molecule is imprinted to select for longer CDR3, we deep-sequenced the mouse TCR $\beta$ repertoire from CD $4 \mathrm{~T}$ cells isolated from 

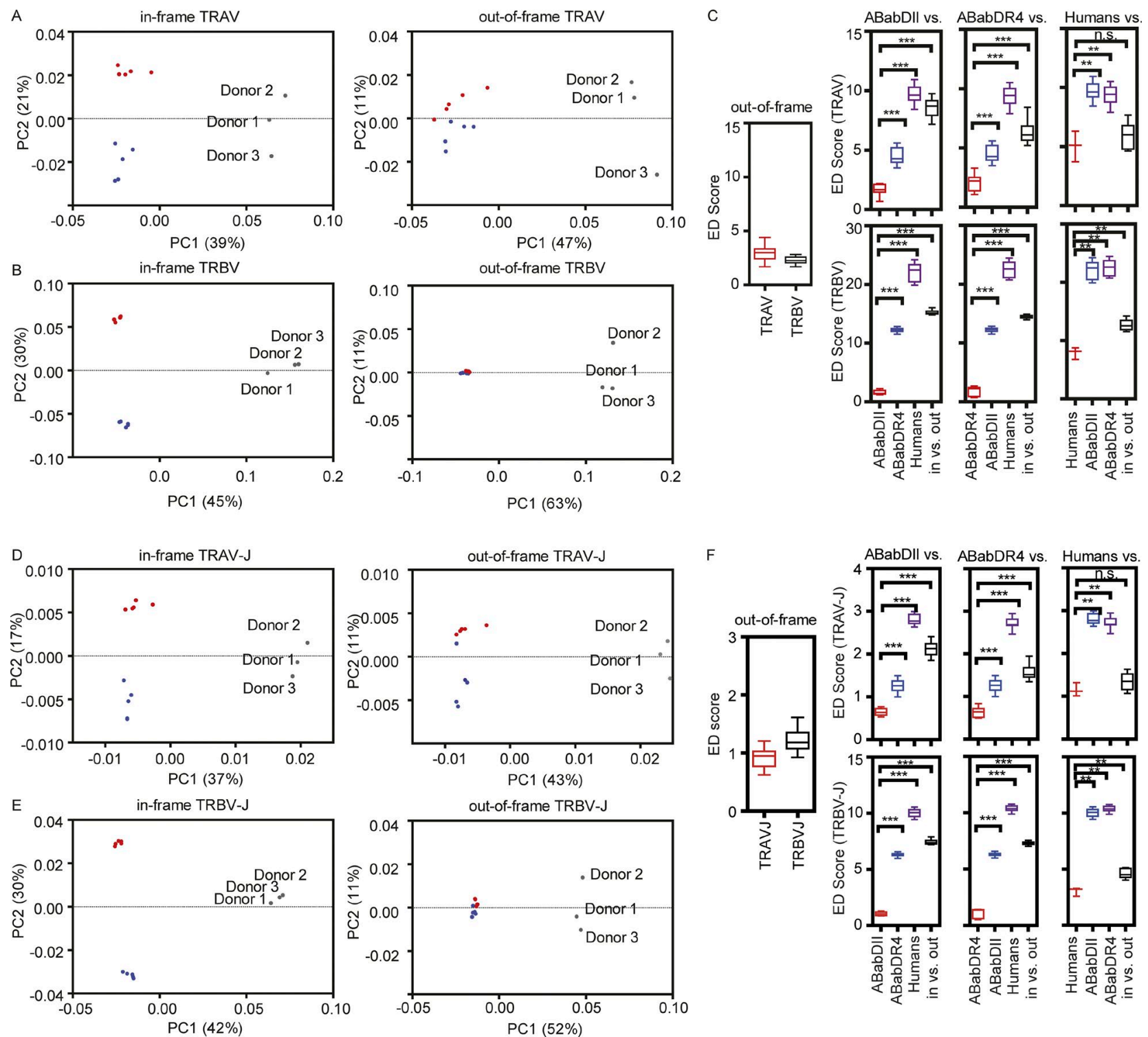

Figure 5. PCA correlations among mice and humans for $\mathbf{V}$ and $\mathbf{V}-\mathbf{J}$ usage. PCA shows the correlation between ABabDII mice (blue dots), ABabDR4 mice (red dots), and human donors (gray dots) for their TRAV usage (A) and TRBV usage (B) of unique TCR clonotypes. (Left) PCA of in-frame sequences; (right) PCA for out-of-frame sequences. TRAV1-1, TRAV1-2, TRBV5-1, and TRBV6-1 were excluded. Each dot represents an individual of ABabDII mice, ABabDR4 mice, or humans. Proportions of variance (PC1 and PC2) are indicated at the axis. (C) Comparisons of $V$ segment usages restricted to the same or different MHC alleles. (Left) Similarity comparisons of out-of-frame $V$ gene usages in ABabDII and ABabDR4. (Right, top and bottom lanes) Similarity comparisons of in frame $V$ segment usages within and between groups of ABabDII mice, ABabDR4 mice, and humans and to the out-of-frame sequences. (Top) TCR $\alpha$ (TRAV) V segments; (bottom) TCR $\beta$ (TRBV) V segments. ( $D$ and E) PCA of TRAV-J (D) and TRBV-J (E) pairing usage of unique TCR clonotypes, arranged the same as in $A$ and $B$. (F) Comparisons of $V-J$ pairing usages restricted to the same or different $\mathrm{MHC}$ allele(s), arranged the same as in $\mathrm{C}$. ${ }^{* *}, \mathrm{P} \leq 0.001$; ${ }^{*}, 0.001 \leq P<0.05$; and ${ }^{*}, 0.05 \leq P<0.1$; n.s., not significant (Mann-Whitney test, two-tailed). ED, Euclidean distance. Data are from ABabDII mice ( $\left.n=5\right)$, ABabDR4 mice $(n=5)$, and humans $(n=3)$. Fig. S4 provides PCA analysis of J segment usages.

three C57BL/6 mice. Mouse TCR $\beta$ selected on the mouse I-A ${ }^{\mathrm{b}}$ molecule showed a rather similar mean CDR3 length to ABabDR 4 mice and human postselection (Fig. 7, B and C). Thus, selection of TCR $\beta$ chains with shorter CDR3 was a specific feature of ABabDII mice.

CDR3 length is the net result of exonuclease and terminal deoxynucleotidyl transferase (TdT) activity. ABabDII,
ABabDR 4, and C57BL/6 mice had similar exonuclease and $\mathrm{TdT}$ activity, reflected by their almost identical number of bp deletions and insertions in the CDR 3 region of TCR $\alpha$ (Fig. 7 D) and $\beta$ chains (Fig. 7, D and E). Compared with mice, humans revealed, on average, more deletions and insertions and, thus, had more exonuclease and TdT activity. When analyzing the CDR3 length in groups according to their V 
A

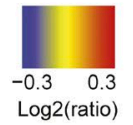

ABabDII ABabDR4 human

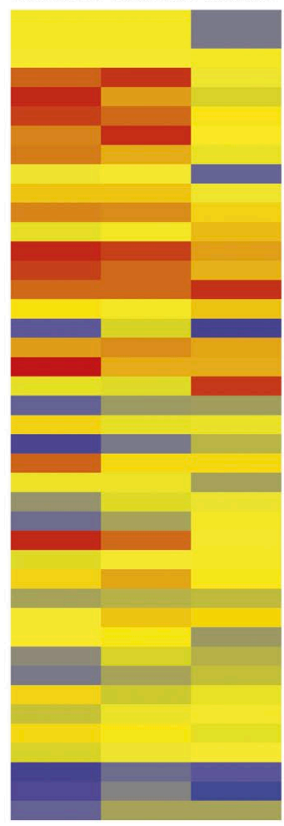

TCRa

TRAV1-1
TRAVV1-2
TRAV2
TRAV3
TRAV3
TRAV4
TRAV5
TRAV6
TRAV8-1
TRAV10
TRAV12-1
TRAV8-2
TRAV8-3
TRAV13-1
TRAV12-2
TRAV8-4
TRAV13-2
TRAV14/DV4
TRAV9-2
TRAV12-3
TRAV8-6
TRAV16
TRAV17
TRAV19
TRAV20
TRAV21
TRAV22
TRAV23/DV6
TRAV24
TRAV25
TRAV26-1
TRAV27
TRAV29/DV5
TRAV30
TRAV26-2
TRAV34
TRAV35
TRAV36/DV7
TRAV38-1
TRAV38-2/DV8
TRAV39
TRAV40
TRAV41
TRA

TCR $\beta$

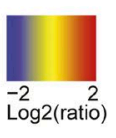

ABabDII ABabDR4 Human

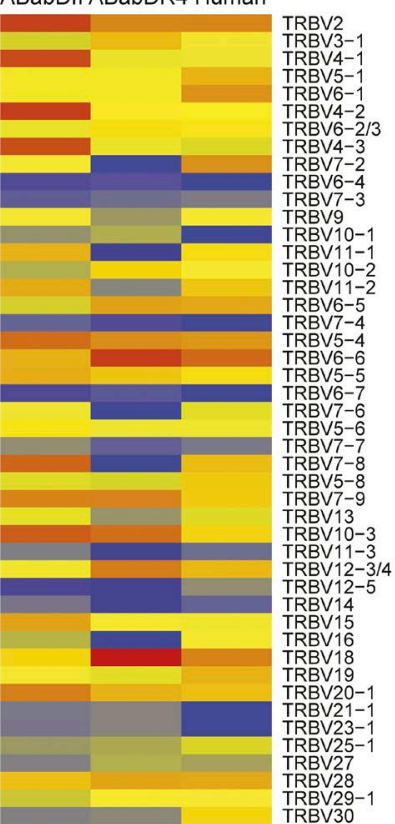

Figure 6. Grouped V gene analysis. (A) Heat maps of TCR $V$ gene usage changes after thymic selection. Red represents the $V$ genes that were overpresented after thymic selection, yellow were the ones unchanged, and gray to blue were ones that were underrepresented. Values were calculated as $\log _{2}$ of the ratio of Frequency $V_{\text {in-frame }} /$ Frequency $V_{\text {out-of-frame. }}(B) V$ genes were grouped into overrepresented, unchanged, or underrepresented, and their CDR3 length distributions are shown in bars (mean \pm SD). Gaussian distributions were assumed and are shown in lines for all groups. Data are from ABabDII mice $(n=5)$, ABabDR4 mice $(n=$ $5)$, and humans $(n=3)$.
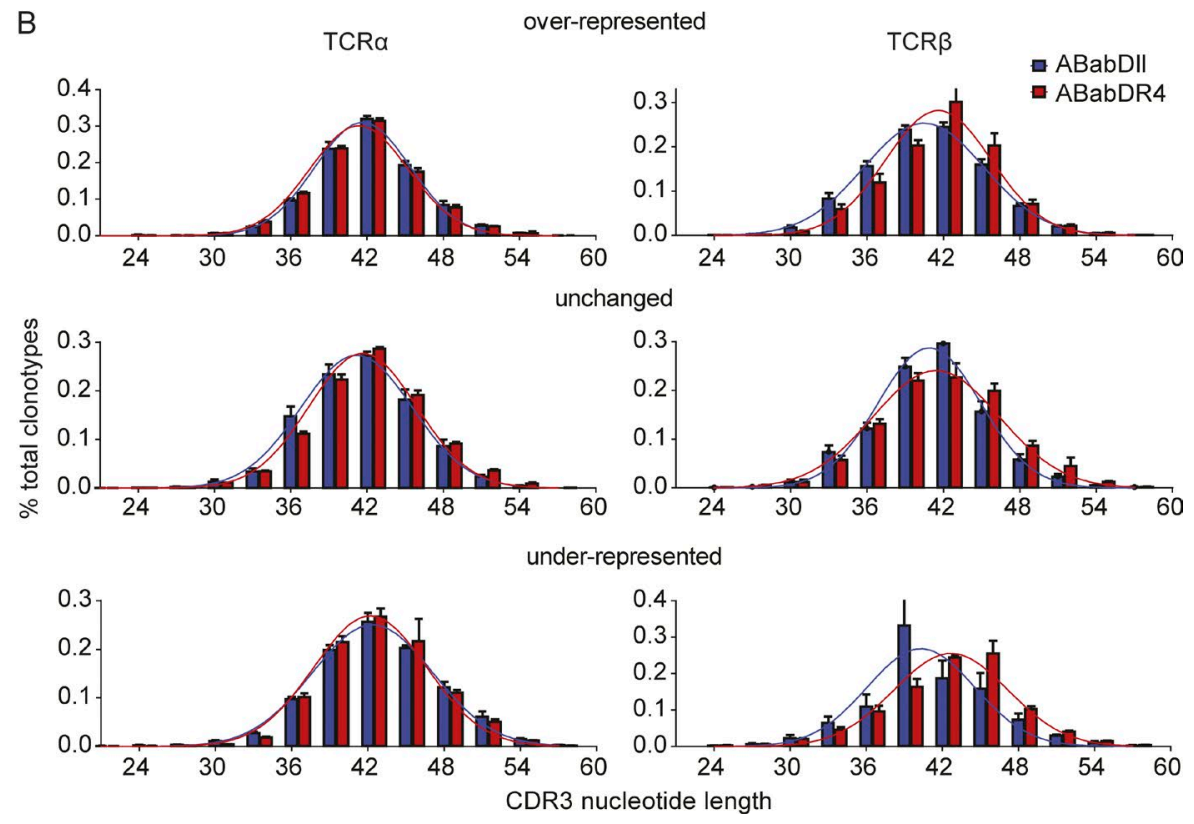

gene usage frequencies, the underrepresented $\mathrm{V} \beta$ genes in ABabDII mice had, on average, the shortest CDR3 length, whereas in ABabDR 4 mice, they had, on average, the longest CDR3 length (Fig. 6 B).

\section{Shared TCR $\alpha$ and $\beta$ clonotypes}

The number of shared clonotypes (based on amino acid sequences) after selection within and between the two mouse strains and humans was strikingly greater than if the repertoire is created randomly (Fig. S5, A and B; Robins et al., 2010).
More shared clonotypes were detected within, compared with between, groups (Fig. 8), and ABabDR 4 shared more clonotypes among each other (Jaccard index: $0.224 \pm 0.006$ for TCR $\alpha$ and $0.076 \pm 0.003$ for TCR $\beta$ ) than ABabDII mice $\operatorname{did}(0.193 \pm 0.006$ for TCR $\alpha$ and $0.067 \pm 0.002$ for TCR $\beta)$.

The number of shared clonotypes beyond MHC restriction was surprisingly high, and the number of shared TCR $\alpha$ clonotypes $(0.189 \pm 0.006)$ was significantly greater than shared TCR $\beta(0.041 \pm 0.002)$ between ABabDII and ABabDR 4 mice, likely because of one compared with two 

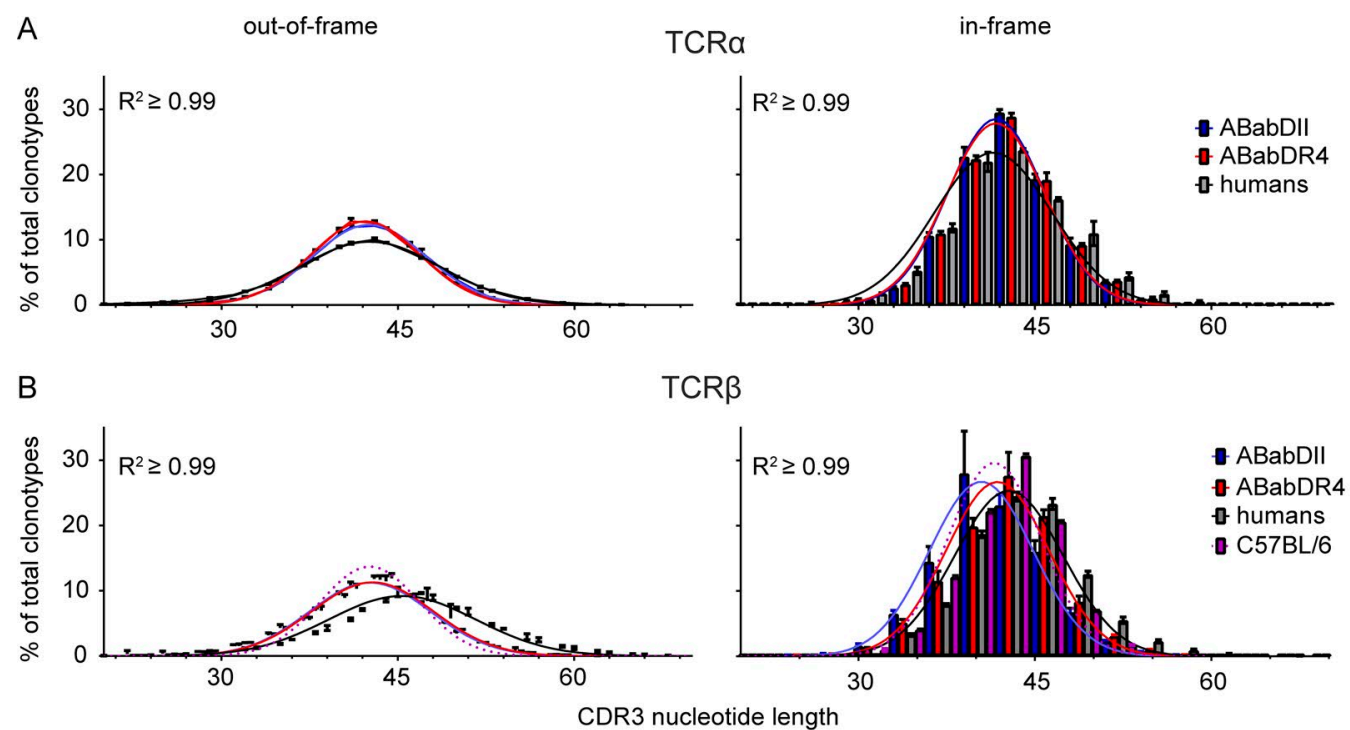

TCR $\beta$
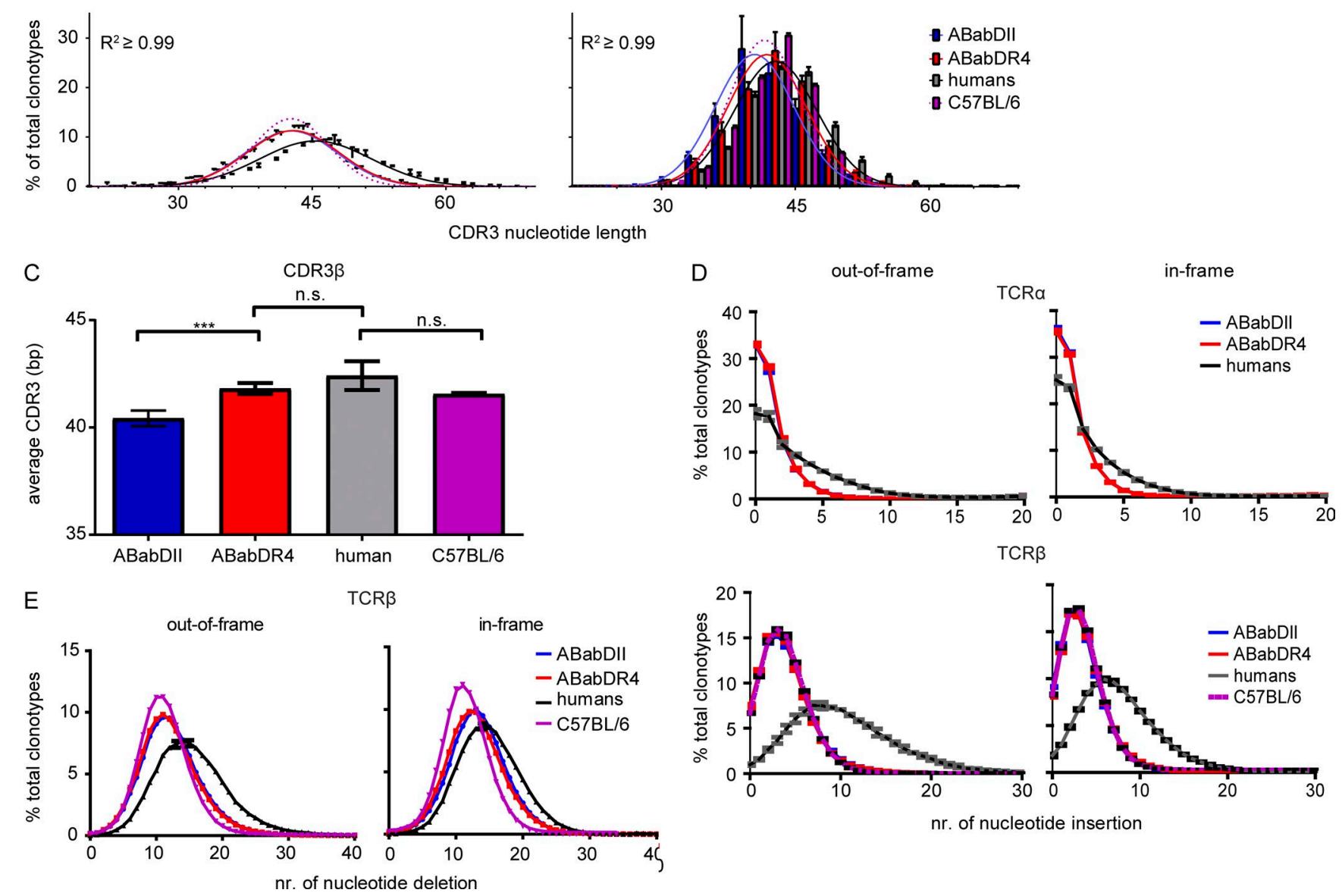

Figure 7. CDR3 region analysis. CDR3 length distribution of TCR $\alpha(A)$ and TCR $\beta(B)$ clonotypes. For the in-frame clonotypes, the frequencies of different CDR3 lengths for ABabDII mice, ABabDR4 mice, humans, and C57BL/6 mice (only TCR $\beta$ ) are shown in bar diagrams. For the out-of-frame clonotypes, only the mean frequency and SD for each CDR3 length are shown for each group at the corresponding length. Gaussian distributions were assumed and are shown as lines for all groups, including the C57BL/6 CDR3 $\beta$ (purple, dotted lines; $R^{2} \geq 0.99$ for all samples). (C) Comparison of means of CDR3 $\beta$ lengths among ABabDII, ABabDR4, and C57BL/6 mice and humans. (D) Frequency of TCRs with the same number of CDR3 nucleotide insertions for TCR $\beta$ chains; insertions in C57BL/6 mice were included (purple dotted lines). (E) Frequency of TCRs with the same number of CDR3 nucleotide deletion of TCR $\beta$ chains from ABabDII mice, ABabDR4 mice, humans, and C57BL/6 mice. ( $D$ and $E$, left) Out-of-frame clonotypes from TCR $\alpha$ (top)/ $\beta$ (bottom). (D and $E$, right) In-frame. For all panels, ${ }^{* *}, 0.001 \leq \mathrm{P}<0.05$; n.s., not significant (Mann-Whitney test, two-tailed). Data are shown as means \pm SD. Data are from ABabDII $(n=5)$, ABabDR4 $(n=5)$, and C57BL/6 $(n=3)$ mice and humans $(n=3)$.

somatic recombination events. ABabDII and ABabDR4 generated more shared TCR $\alpha$ and $\beta$ than they shared with humans (ABabDII with humans: TCR $\alpha 0.072 \pm 0.017$ and $\operatorname{TCR} \beta 0.0057 \pm 0.001 ; \mathrm{ABabDR} 4: \mathrm{TCR} \alpha 0.082 \pm 0.020$ and $\operatorname{TCR} \beta 0.0070 \pm 0.001)$, most likely because of the higher genetic similarity between the two mouse strains. Notably, random recombination would yield virtually no shared clonotypes within $2.5 \times 10^{5} \mathrm{CD} 4 \mathrm{~T}$ cells. The shared clonotypes within and among groups cumulated linearly with the increase in total clonotypes (Fig. S5 B). 

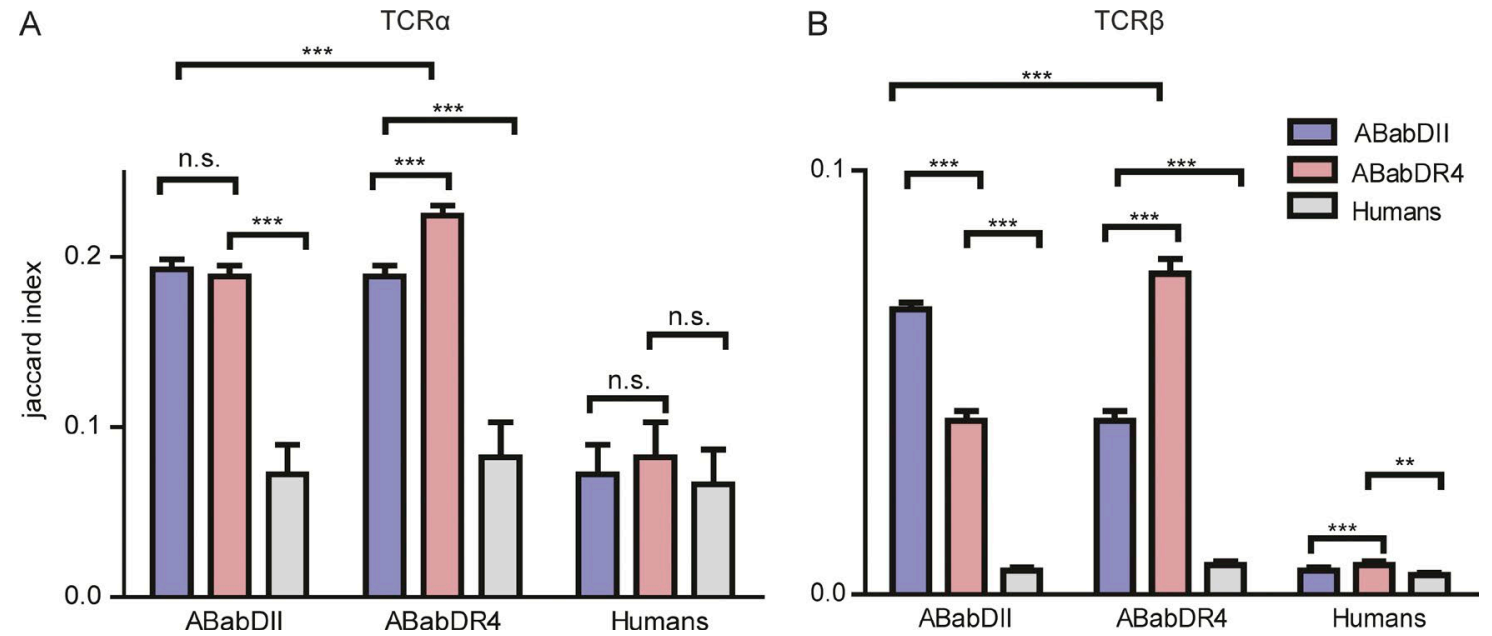

Figure 8. TCR shared repertoire analysis from ABabDII mice, ABabDR4 mice, and humans. Jaccard index scores within and between groups of $A B a b-$ DIl mice, ABabDR4 mice, and human samples for both TCR $\alpha(A)$ and $\operatorname{TCR} \beta(B) .{ }^{* *}, 0.001 \leq P<0.05 ;{ }^{* *}, P \leq 0.001$ (Mann-Whitney test, two-tailed). The data shown are means \pm SD from ABabDII mice $(n=5)$, ABabDR4 mice $(n=5)$, and humans $(n=3)$. Additional information in Fig. S5.

\section{Stronger CD4 T cell responses in} ABabDR4 compared with DR4 mice

We investigated whether ABabDR 4 mice could more efficiently respond to immunization than did DR 4 mice expressing a mouse TCR repertoire selected on HLA-DR4. Therefore, we immunized ABabDR 4 and DR 4 mice with the two HLA-DR4-presented peptides derived from hemagglutinin $\left(\mathrm{HA}_{307-319}\right)$ or PTPN11 mut. PTPN11 mut is a somatic mutation in cancer with a single amino acid substitution but is otherwise identical to the mouse homologue. The percentage of IFN- $\gamma^{+} \mathrm{CD} 4 \mathrm{~T}$ cells in response to both peptides was significantly higher in ABabDR4 compared with DR 4 mice $(0.37 \% \pm 0.22 \%$ vs. $0.04 \% \pm$ $0.04 \%$ for $\mathrm{HA}_{307-319}$ and $0.15 \% \pm 0.06 \%$ vs. $0.03 \% \pm 0.02 \%$ for PTPN11 mut peptide, respectively; Fig. 9). The data suggest that ABabDR 4 have more $\mathrm{HA}_{307-319}$ and PTPN11 1 mut CD4 $\mathrm{T}$ cell precursors than DR4 mice.

\section{DISCUSSION}

We felt that the controversial discussion about whether and how the TCR and MHC coevolved reached a dead end with good arguments for either site. This is because, in most cases, single TCR-pMHC interactions were analyzed, either by resolving crystallographic structures or by analyzing mutations in the germline-encoded CDR1 and CDR2 (Marrack et al., 2008; Rossjohn et al., 2015). Although the data provided convincing evidence for TCR-MHC coevolution, inherent in the immune system, there are usually exceptions to that rule, so that it is not always easy to distinguish what is the exception and what is the rule. For example, a TCR germline bias (Garcia et al., 2009) is difficult to reconcile with the observation that $85 \%$ of the thymocytes do not receive a selection signal and, therefore, apparently lack a sufficient affinity for self-pMHC and that only $7.5 \%$ of the thymocytes are MHC or pMHC cross-reactive (Blackman et al., 1986; Merken-
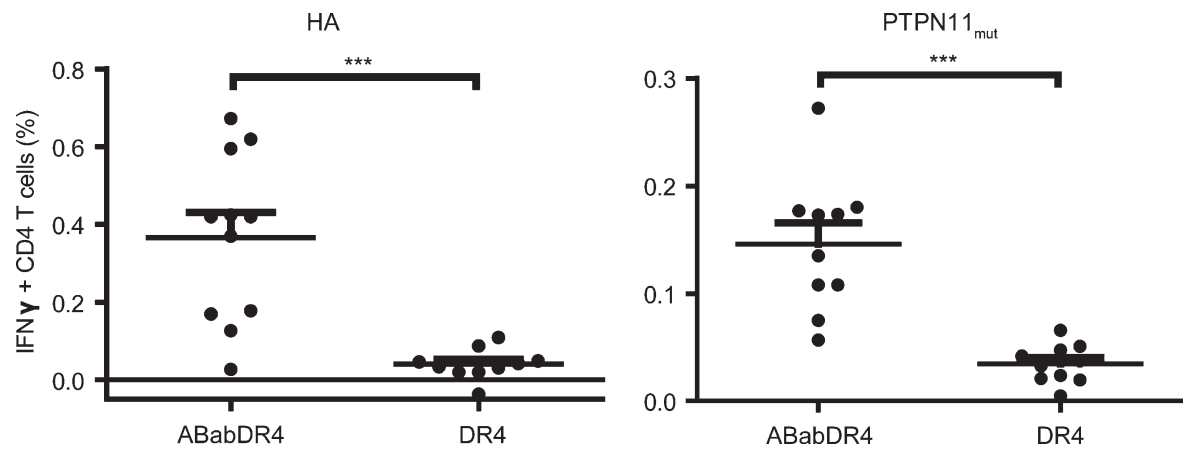

Figure 9. Comparison of CD4 T cell responses against two HLA-DR4 epitopes between DR4 and ABabDR4 mice. ABabDR4 and DR4 mice were immunized twice with hemagglutinin peptide 307-319 (HA) or PTPN11G503A peptide 492-506 (PTPN11 mut). At 2 wk after the second immunization, CD4 $T$ cell responses were detected with peptide restimulation of draining LN cells, followed by intracellular IFN- $\gamma$ staining. Percentages of IFN $-\gamma^{+}$CD4 T cells were measured by flow cytometry. Gates were set on live $\mathrm{CD}^{+}$lymphocytes. Each dot represents one mouse. Results are from two experiments combined and shown as mean \pm SD. ${ }^{* *}, \mathrm{P}<0.001$ (MannWhitney test, two-tailed). 
schlager et al., 1997; Zerrahn et al., 1997; Huseby et al., 2005; McDonald et al., 2015). Therefore, we addressed the issue differently, based on the assumption that evolving differences in the inherent affinity between TCR and MHC in mice and humans are subtle and that thymic selection is the most sensitive read-out to detect such differences. We investigated the human $\alpha \beta$ TCR repertoire because previous studies focused mainly on mouse TCR-MHC interactions, and we analyzed the polyclonal repertoire to encompass the ability of a single MHC allele to select $\mathrm{T}$ cells with any possible, functionally rearranged TCR. By comparing the pre- and postselection repertoire selected on a single mouse or human MHC II allele, we indirectly addressed the inherent germline-encoded affinity for any human $\mathrm{V} \alpha(\mathrm{J} \alpha)$ or $\mathrm{V} \beta(\mathrm{J} \beta)$ segment, which evolved during the some 70-million-year divergence of rodents and humans. Our conclusions became apparent only through massive parallel TCR deep sequencing.

Both TCR $\alpha$ and TCR $\beta$ V-J gene usage in CD 4 T cells as well as $\mathrm{V}-\mathrm{J}$ combinatorial frequencies are highly biased, dramatically limiting the theoretically possible $\mathrm{T}$ cell repertoire, which was known for the TCR $\beta$ repertoire (Robins et al., 2010; Rubelt et al., 2016). The nonrandom usage is hardwired in the human TCR gene loci. It is imprinted in the postselection repertoire but shaped by the respective selecting MHC II molecule, shown by the PCA, and the higher number of shared clonotypes within than between the two mouse lines. Surprisingly, many TCR $\beta$ clonotypes were shared, and even more TCR $\alpha$ clonotypes were shared between humans and human MHC II-expressing mice. ABabDR 4 mice shared more TCR clonotypes $(11 \% \pm 0.3 \% \mathrm{TCR} \alpha$ and $1.3 \pm 0.1 \%$ TCR $\beta$ chains) with humans than ABabDII mice did $(9.6 \%$ $\pm 0.2 \% \mathrm{TCR} \alpha$ and $1.1 \pm 0.2 \% \mathrm{TCR} \beta)$. The abundance of shared TCR $\alpha$ or TCR $\beta$ single chains between different species and, independent of the MHC II profile, suggests that $\alpha \beta$ chain combinatorial pairing has a larger role for creating diversity than previously thought (Arstila et al., 1999). We could not detect more shared clonotypes between ABabDR 4 mice and the only HLA-DR $4^{+}$human, which is not surprising because humans bear six MHC II alleles, and which TCR is restricted to which $\mathrm{MHC}$ II allele is not known.

Mouse MHC II molecules almost perfectly select a human TCR repertoire, but only, almost. Basically, all human TCR $\alpha$ $\mathrm{V}-\mathrm{J}$ and TCR $\beta \mathrm{V}-\mathrm{D}-\mathrm{J}$ gene combinations were detected in the postselection repertoire of ABabDII mice, demonstrating that "structurally coded recognition motifs for MHC" (Marrack et al., 2008; Garcia et al., 2009) have been selected and fixed in most human $\mathrm{V}$ genes before mouse-human divergence. However, ABabDII mice had reduced thymic output and a greater clonality. The difference in I-A ${ }^{\mathrm{b}}$ and HLA-DR4 in selecting a human TCR repertoire became clearly visible in the global comparison when ABabDR 4 mice generated 30\% more of both TCR $\alpha$ and TCR $\beta$ unique clonotypes (amino acids) than did ABabDII mice. This provides a strong hint that mouse MHC II molecules, at least I-A $\mathrm{A}^{\mathrm{b}}$, do not select as efficiently a diverse, human $\alpha \beta$ TCR repertoire as human MHC II molecules.
The increased TCR repertoire selected by HLA-DR4 compared with $\mathrm{I}-\mathrm{A}^{\mathrm{b}}$ molecules is likely due to a slightly increased inherent affinity, likely in the CDR 1 and CDR2 regions (Marrack et al., 2008), of many human V $\alpha$ genes for HLA-DR 4. The increased TCR $\beta$ repertoire in ABabDR4, compared with ABabDII, mice is directly reflected in the CDR3 length. ABabDII and ABabDR4 mice revealed similar CDR3 $\beta$ length distribution in the preselection repertoire. After selection, the mean length of CDR3 $\beta$ selected by human MHC II in ABabDR 4 mice and humans was one amino acid longer than that selected by mouse MHC II. The mean, shorter CDR3 $\beta$ was not seen in C57BL/6 mice, where the TCR and MHC were species compatible. Thus, the most likely explanation is that species-specific TCRs evolved to have an optimal intrinsic affinity for their own $\mathrm{MHC}$ or vice versa. Assuming that the intrinsic affinity is not optimal between many human TCRs and mouse MHC II, the peripheral CD4 $\mathrm{T}$ cell repertoire in ABabDII mice had to adopt a shorter CDR3 domain to become positively selected (Gilfillan et al., 1995; Marten et al., 1999; Yassai et al., 2002). Shorter CDR3 domains increase the risk that T cells will be cross-reactive (Gavin and Bevan, 1995; Huseby et al., 2008). In line with that finding, ABabDR 4 mice had more peripheral Tcon cells, compared with ABabDII mice and, interestingly, the frequency of Treg within the CD4 T cell population was substantially higher in ABabDII (19.9 $\pm 4.4 \%)$ compared with ABabDR 4 mice $(10.8 \pm 4.0 \%)$. Thus, we assume that CD4 $\mathrm{T}$ cells selected for short CDR3 of human TCRs by mouse MHC II are at higher risk of ending as Tregs because of cross-reactivity. Collectively, the interspecies incompatibility between TCR and MHC further supports TCR-MHC coevolution after divergence of the two species. However, the TCR repertoires selected by the closest homologues, e.g., I-A ${ }^{b}$ and HLA-DQ, need to be analyzed.

In ABabDII mice, underrepresented $V$ genes seem to have suboptimal affinity for the I-A ${ }^{b}$ molecule because their CDR3 were, on average, the shortest. In contrast, the underrepresented V genes selected by HLA-DR 4 had, on average, the longest CDR3. Thus, the underrepresented human $\mathrm{V}$ genes in ABabDII mice may have retained or gained affinity for HLA-DR4 but lost it for I-A ${ }^{b}$. On the other hand, the underrepresented $\mathrm{V}$ genes in ABabDR4 mice may have a too-high, inherent affinity for HLA-DR4, assuming that longer CDR3 decrease the affinity. The picture may change with different MHC II alleles; each of which, may have a set of preferred and nonpreferred $\mathrm{V}$ genes (Sharon et al., 2016). We hypothesize that different, inherent affinity of any $\mathrm{V}$ segment for any $\mathrm{MHC}$ allele is adjusted by CDR3 length, ensuring that $\mathrm{T}$ cells with any $\mathrm{V}$ segment can be positively selected by any MHC allele, which is supported by the diverse human TCR repertoire in ABabDII mice. HLA-DR4 is capable, but less efficient, in selecting a mouse TCR repertoire than $I-A^{b}$ because CD4 $\mathrm{T}$ cell responses were less efficient in HLA-DR4 transgenic, compared with ABabDR4, mice. 
Mice generate, on average, a shorter TCR $\beta$ CDR3 region than do humans, which can be seen in the preselection repertoire. Surprisingly, the human recombination machinery evolved to both excise and add more nucleotides in the TCR $\beta$ V-D and D-J junctional regions, which is executed by combined exonuclease and TdT activity. Both enzymatic activities might increase TCR diversity. This evolutionary process provides a reasonable explanation for the larger $\mathrm{T}$ cell repertoire in humans, which was estimated to be 20 -fold higher than that of mice (Arstila et al., 1999; Casrouge et al., 2000; Nikolich-Žugich et al., 2004; Vrisekoop et al., 2014).

In conclusion, our findings suggest that human TCR $\alpha$ and TCR $\beta V$ genes acquired an inherent affinity for MHC II before separation of rodents and humans. Afterward, human MHC and TCR gene loci further coevolved to maintain inherent affinity, and in order to compensate for nonrandom $\mathrm{V}(\mathrm{D}) \mathrm{J}$ usage, to increase $\mathrm{T}$ cell diversity by focusing on larger nontemplate-encoded CDR 3 diversity. Our data also suggest that CDR3 length adjusts for different inherent $\mathrm{V}$ segmentMHC affinity and that T cells with shorter CDR3 $\beta$ are at increased risk of becoming Tregs.

\section{MATERIALS AND METHODS \\ Mice}

All mouse studies were performed in accordance with institutional, state, and federal (Landesamt für Arbeitsschutz, Gesundheitsschutz und technische Sicherheit, Berlin, Germany) guidelines. C57BL/6 and HLA-DR 4 mice were purchased from The Jackson Laboratory and Taconic, respectively. ABabDII transgenic mice have been previously described ( $\mathrm{Li}$ et al., 2010). ABabDR 4 mice were established by crossing ABab transgenic mice (Li et al., 2010) to HLA-DR4 mice (Ito et al., 1996) and selecting mice homozygous for human TCR $\alpha$ and TCR $\beta$ gene loci, HLA-DR 4 transgene, as well as mouse TCR $\alpha, \operatorname{TCR} \beta$, I-E $\alpha$, and I-A $\beta$ deficiency. The genotype of the mice was confirmed by PCR. Mice were bred in the Max-Delbrück-Center animal facility under specific pathogen-free condition and were on a mixed 129SV, C57BL/6, and BALB/c genetic background. Mice aged between 8 and 16 wk were used in this study.

\section{Human donors}

Three healthy human donors, aged 30, 48, and $60 \mathrm{yr}$ at the time of blood collection, volunteered to donate blood with informed consent. Blood collecting and processing was performed according to human experimental guidelines under license EA4/046/10 (Ethikkommission). The MHC II profiles were determined by genotyping (Zentrum für Humangenetik und Laboratoriumsdiagnostik, Martinsried, Germany). Details are as follows: donor 1: HLA-DRB1 08:01, 11:12; HLA-DRB3 02; HLA-DQB1 03:01, 04:02; HLA-DPB1 03:01, 04:02; donor 2: HLA-DRB1 04:01, 15:01; HLA-DRB4 01:03; HLA-DRB5 01:01; HLA-DQA1 01:02, 03:01; HLA-DQA1 01:02, 03:01; HLA-DQB1 03:02, 06:02; HLA-DPA1 01:03; HLA-DPB1 04:01; and donor 3:
HLA-DRB1 01:01, 13:01; HLA-DRB3 02:02; HLA-DQA1 01:01, 01:03; HLA-DQB1 05:01, 06:03; HLA-DPA1 01:03; HLA-DPB1 04:01.

\section{Flow cytometry}

Fluorochrome-conjugated antibodies specific for mouse CD4 (GK1.5), CD8a (53-6.7), CD5 (53-7.3, isotype: rat IgG2a, к), IFN- $\boldsymbol{\gamma}$ (XMG1.2), CD45 (30-F11, isotype: rat IgG2b, к), CD326 (EpCAM, G8.8, isotype: rat IgG2 $\alpha, \kappa)$, I-Ab (AF6-120.1), CD11c (N418), and FoxP3 (MF-14), and human CD3 (HIT3a), CD8a (HIT8a), CD4 (OKT4), CD45RA (H1100), CD45RO (UCHL1), and CD62L (DREG-56) were obtained from BioLegend. Mouse CD $3 \varepsilon$ (145-2C11), CD69 (H1.2F3, isotype: Armenian hamster $\operatorname{IgG})$, Ly51 (6C3, isotype: rat IgG2a, $\kappa$ ), and HLA-DR (L243) specific antibodies were purchased from BD. The TCR V $\beta$ repertoire kit (IOTest Beta Mark) was purchased from Beckman Coulter. UEA I lectin was obtained from GeneTex. Thymus, spleen, and LNs from 1-2-mo-old C57BL/6, ABabDII and ABabDR4 mice were isolated. Cells were obtained by mashing the organs through a $0.45-$ $\mu \mathrm{m}$ cell strainer. Isolation of thymic DCs and epithelial cells was performed as published (Xing and Hogquist, 2014). In brief, thymic lobes were digested in enzyme solution (RPMI-1640 medium with 0.05\% Liberase TH and 100 $\mathrm{U} / \mathrm{ml}$ of DNase I) at $37^{\circ} \mathrm{C}$ for $20 \mathrm{~min}$. Single cells were then stained with antibodies specified in the respective figure legends and analyzed by flow cytometry (FACSCanto II; BD). FoxP3 staining was performed with True-Nuclear transcription factor buffer set from BioLegend.

\section{FACS sorting}

For mouse CD4 T cells, pooled cells from mouse spleen and LNs were collected. For human naive $\left(\mathrm{CD}_{45 \mathrm{RO}^{-}}\right.$and CD62 $\mathrm{L}^{+}$) CD4 $\mathrm{T}$ cell isolation, $\sim 50 \mathrm{ml}$ fresh blood from human donors was collected, and PBMCs were isolated by the Ficoll density centrifugation method. The cells were sorted by a FACS sorter (FACSARIA III;BD), and the purity for all samples was $>95 \%$.

\section{Assay for detection of MMTV}

Mouse CD4T cells and CD19 cells from spleens of C57BL/6, DR 4, ABabDII, and ABabDR4 mice were purified using mouse $\mathrm{CD}^{+} \mathrm{T}$ cell isolation kit and CD19 MicroBeads (Miltenyi Biotec). Subsequently, the purified CD4 T cells were labeled with CellTrace Violet (Thermo Fisher Scientific). $3 \times 10^{5}$ labeled CD4 T cells were co-cultured with 1.5 $\times 10^{6}$ CD19 cells from different mouse strains at a ratio of $1: 5$ in a 96 -well, round-bottom plate for $84 \mathrm{~h}$ at $37^{\circ} \mathrm{C}$, with $5 \% \mathrm{CO}_{2}$. Measurement of the proliferated CD4 $\mathrm{T}$ cells was accessed by flow cytometry.

\section{Genomic DNA isolation and TCR deep sequencing}

Genomic DNA was extracted with the QIAGEN blood and tissue kit, quantified with a NanoDrop 1000 (Thermo Fisher 
Scientific), and stored at $-80^{\circ} \mathrm{C} . \mathrm{TCR} \alpha$ and TCR $\beta$ deep sequencing and quantification was performed on an immunoSEQ platform (Adaptive Biotechnologies). The technique has a sensitivity of 1 in $200,000 \mathrm{~T}$ cells and was optimized to minimize the effect of PCR bias introduced in the first multiplex PCR step (Robins et al., 2009; Carlson et al., 2013). 1.2 $\mu \mathrm{g}$ of genomic DNA, which corresponds to $\sim 2.5 \times 10^{5}$ mouse and $\sim 1.8 \times 10^{5}$ human CD4 $\mathrm{T}$ cells, was sequenced for each sample. TCR sequences were delineated according to the definition established by the International ImMunoGeneTics Information System collaboration.

\section{Immunization}

ABabDR 4 and DR 4 mice were immunized twice at an interval of $4 \mathrm{wk} .80 \mu \mathrm{g}$ hemagglutinin peptide $\mathrm{HA}_{307-319}(\mathrm{KYV}$ KQNTLKLATG) or mutant peptide PTPN11 ${ }_{492-506}$ (KTI QMVRSQRSMVQ; G503A mutation), mixed with $100 \mu \mathrm{l}$ IFA, and $50 \mu \mathrm{g} \mathrm{CpG}$ oligonucleotides were injected s.c. on both sides of the tail base of each mouse. $14 \mathrm{~d}$ after the second immunization, the draining LNs were isolated, single cells were restimulated in vitro for $12 \mathrm{~h}$ with the respective peptides, and the IFN- $\gamma$ production by CD4 T cells was measured intracellularly using the kit and protocol from BD (Cytofix/Cytoperm kit).

\section{Data analysis}

Data analysis and statistics were performed in Excel (Microsoft), R (R Foundation for Statistical Computing), and Prism (GraphPad Software).

Gene segment (V, J and V-J pairing) frequencies. Calculation of random distribution frequencies was estimated by the reciprocal of the total number of functional TCR genes (V, J, or V-J pairing).

iCHA01 estimator. The TCR $\alpha$ and $\beta$ repertoire sizes of ABabDII and ABabDR 4 mice and humans were estimated based on the deep-sequenced samples using iCHAO1 estimator provided with the immunoSEQ platform (Chiu et al.,2014).

Inequality Score. Inequality (Gini index) analysis on the in-frame TCR amino acid clonotypes was based on the Lorenz curve.

PCA. PCA was performed based on $\mathrm{V}, \mathrm{J}$, or $\mathrm{V}-\mathrm{J}$ combinatorial frequencies from ABabDII and ABabDR 4 mice and humans with the "prcomp" function in $\mathrm{R}$ software without data normalization (centralizing data). TRAV1, TRBV5-1, and TRBV6-1 were excluded from the analysis because they were known to be missing in the transgenic mouse repertoire.

Euclidean distance. The Euclidean distance (ED score) was calculated, as shown in Eq. 1, to evaluate the similarities of $\mathrm{V}$ gene or V-J pairing usage frequencies within and between different groups:

$$
\text { ED score }=\sqrt{\sum_{i}\left(V_{\text {group } 1}^{i}-V_{\text {group } 2}^{i}\right)^{2}} .
$$

Estimation of Gaussian CDR3 length distribution. All CDR3 lengths from ABabDII and ABabDR 4 mice and humans were assumed to have a Gaussian distribution $\left(\mathrm{R}^{2}>0.99\right)$. We used the variance (square of the SD) of the predicted Gaussian curve to depict the width of the CDR3 distributions.

Absolute number of shared clonotypes. The number of shared clonotypes from any two of the reshaped samples was calculated using the "intersect" function in R software, package tcR (Nazarov et al., 2015).

Jaccard index for similarity analysis. The $\alpha \beta$ TCR similarities between any two samples were evaluated with the Jaccard index, which uses the number of shared TCR clonotypes by the number of total clonotypes from the two samples, as shown in Eq. 2:

$$
J(A, B)=|A \cap B| /|A \cup B|,
$$

where $A$ and $B$ represent $\operatorname{TCR} \alpha$ or $\beta$ repertoires from any two samples.

Sample size. No specified effect size was used to determine sample sizes.

\section{Data availability}

TCR sequencing data underlying this study can be analyzed and downloaded from the Adaptive Biotechnologies immuneACCESS site at https://doi.org/10.21417/B7ZD0D.

\section{Online supplemental material}

Fig. S1 includes MHC II staining of thymic APCs from C57BL/6, ABabDII, and ABabDR 4 mice. Fig. S2 includes additional data related to Fig. 1, showing FoxP3 and CD44 frequencies in C57BL/6, ABabDII, and ABabDR4 mice, including one representative staining and total columns for Treg and $\mathrm{Tcon} \mathrm{V} \beta$ usages in ABabDII and ABabDR 4 mice. Fig. S3 shows CD4T cell responses to MMTV superantigen-presenting CD19 cells from C57BL/6, DR4,ABabDII, and ABabDR4 mice. Fig. S4 includes additional data related to Fig. 5, showing PCAs of TRAJ/BJ usages in ABabDII and ABabDR 4 mice and human donors. Fig. S5 includes additional data related to Fig. 8 , showing the absolute TCR $\alpha / \beta$ clonotypes shared either in total or from the most- to the least-abundant clonotypes among ABabDII and ABabDR 4 mice and human donors.

\section{ACKNOWLEDGMENTS}

We thank M. Obenaus for suggestions in data interpretation, bioinformatic support, and critical reading of this manuscript; $M$. Manzke and $C$. Westen for genotyping the mice; and A. Dhamodaran for critical reading of the manuscript.

This work was supported by the Deutsche Forschungsgemeinschaft through SFB-TR36.

The authors declare no competing financial interests. 
Author contributions: X. Chen developed the concept, performed experiments, analyzed the data, and wrote the manuscript; L. Poncette performed the immunization experiments, analyzed the data, and revised the manuscript; and T. Blankenstein developed the concept, analyzed the data, and wrote the manuscript.

Submitted: 24 October 2016

Revised: 19 June 2017

Accepted: 19 July 2017

\section{REFERENCES}

Adams, J.J., S. Narayanan, M.E. Birnbaum, S.S. Sidhu, S.J. Blevins, M.H. Gee, L.V. Sibener, B.M. Baker, D.M. Kranz, and K.C. Garcia. 2016. Structural interplay between germline interactions and adaptive recognition determines the bandwidth of TCRpeptide-MHC cross-reactivity. Nat. Immunol. 17:87-94. http://dx.doi.org/10.1038/ni.3310

Arstila, T.P., A. Casrouge, V. Baron, J. Even, J. Kanellopoulos, and P. Kourilsky. 1999. A direct estimate of the human $\alpha \beta \mathrm{T}$ cell receptor diversity. Science. 286:958-961. http://dx.doi.org/10.1126/science.286.5441.958

Beringer, D.X., F.S. Kleijwegt, F. Wiede, A.R. van der Slik, K.L. Loh, J. Petersen, N.L. Dudek, G. Duinkerken, S. Laban, A. Joosten, et al. 2015. $\mathrm{T}$ cell receptor reversed polarity recognition of a self-antigen major histocompatibility complex. Nat. Immunol. 16:1153-1161. http://dx.doi .org/10.1038/ni.3271

Blackman, M., J.Yagüe, R. Kubo, D. Gay, C. Coleclough, E. Palmer, J. Kappler, and P. Marrack. 1986. The T cell repertoire may be biased in favor of MHC recognition. Cell. 47:349-357. http://dx.doi.org/10.1016/0092 -8674(86)90591-X

Blattman, J.N., R. Antia, D.J. Sourdive, X. Wang, S.M. Kaech, K. MuraliKrishna, J.D. Altman, and R. Ahmed. 2002. Estimating the precursor frequency of naive antigen-specific CD8 T cells. J. Exp. Med. 195:657664. http://dx.doi.org/10.1084/jem.20001021

Carlson, C.S., R.O. Emerson, A.M. Sherwood, C. Desmarais, M.-W. Chung, J.M. Parsons, M.S. Steen, M.A. LaMadrid-Herrmannsfeldt, D.W. Williamson, R.J. Livingston, et al. 2013. Using synthetic templates to design an unbiased multiplex PCR assay. Nat. Commun. 4:2680. http:// dx.doi.org/10.1038/ncomms 3680

Casrouge, A., E. Beaudoing, S. Dalle, C. Pannetier, J. Kanellopoulos, and P. Kourilsky. 2000. Size estimate of the $\alpha \beta$ TCR repertoire of naive mouse splenocytes. J. Immunol. 164:5782-5787. http://dx.doi.org/10.4049/ jimmunol.164.11.5782

Chiu, C.-H., Y.-T. Wang, B.A. Walther, and A. Chao. 2014. An improved nonparametric lower bound of species richness via a modified goodturing frequency formula. Biometrics. 70:671-682. http://dx.doi.org/10 $.1111 /$ biom. 12200

Dai, S., E.S. Huseby, K. Rubtsova, J. Scott-Browne, F. Crawford, W.A Macdonald, P. Marrack, and J.W. Kappler. 2008. Crossreactive T Cells spotlight the germline rules for $\alpha \beta \mathrm{T}$ cell-receptor interactions with MHC molecules. Immunity. 28:324-334. http://dx.doi.org/10.1016/j .immuni.2008.01.008

Davis, M.M., and P.J. Bjorkman. 1988. T-cell antigen receptor genes and T-cell recognition. Nature. 334:395-402. http://dx.doi.org/10.1038 $1334395 \mathrm{a} 0$

Feng, D., C.J. Bond, L.K. Ely, J. Maynard, and K.C. Garcia. 2007. Structural evidence for a germline-encoded $\mathrm{T}$ cell receptor-major histocompatibility complex interaction 'codon'. Nat. Immunol. 8:975983. http://dx.doi.org/10.1038/ni1502

Garcia, K.C., J.J. Adams, D. Feng, and L.K. Ely. 2009. The molecular basis of TCR germline bias for MHC is surprisingly simple. Nat. Immunol. 10:143-147. http://dx.doi.org/10.1038/ni.f.219
Gavin, M.A., and M.J. Bevan. 1995. Increased peptide promiscuity provides a rationale for the lack of $\mathrm{N}$ regions in the neonatal $\mathrm{T}$ cell repertoire. Immunity. 3:793-800. http://dx.doi.org/10.1016/1074-7613(95)90068-3

Gilfillan, S., C. Benoist, and D. Mathis. 1995. Mice lacking terminal deoxynucleotidyl transferase: adult mice with a fetal antigen receptor repertoire. Immunol. Rev. 148:201-219. http://dx.doi.org/10.1111/j .1600-065X.1995.tb00099.x

Gras, S., Z. Chen, J.J. Miles, Y.C. Liu, M.J. Bell, L.C. Sullivan, L. KjerNielsen, R.M. Brennan, J.M. Burrows, M.A. Neller, et al. 2010. Allelic polymorphism in the $\mathrm{T}$ cell receptor and its impact on immune responses. J. Exp. Med. 207:1555-1567. http://dx.doi.org/10.1084/jem.20100603

Huseby, E.S., J. White, F. Crawford, T. Vass, D. Becker, C. Pinilla, P. Marrack, and J.W. Kappler. 2005. How the T cell repertoire becomes peptide and MHC specific. Cell. 122:247-260. http://dx.doi.org/10.1016/j.cell 2005.05 .013

Huseby, E.S., J.W. Kappler, and P. Marrack. 2008. Thymic selection stifles TCR reactivity with the main chain structure of MHC and forces interactions with the peptide side chains. Mol. Immunol. 45:599-606. http://dx.doi.org/10.1016/j.molimm.2006.03.025

Ito, K., H.J. Bian, M. Molina, J. Han, J. Magram, E. Saar, C. Belunis, D.R. Bolin, R. Arceo, R. Campbell, et al. 1996. HLA-DR4-IE chimeric class II transgenic, murine class II-deficient mice are susceptible to experimental allergic encephalomyelitis. J. Exp. Med. 183:2635-2644. http://dx.doi.org/10.1084/jem.183.6.2635

Jameson, S.C., K.A. Hogquist, and M.J. Bevan. 1995. Positive selection of thymocytes. Annu. Rev. Immunol. 13:93-126. http://dx.doi.org/10.1146 /annurev.iy.13.040195.000521

Kievits, F., P. Ivanyi, P. Krimpenfort, A. Berns, and H.L. Ploegh. 1987. HLArestricted recognition of viral antigens in HLA transgenic mice. Nature. 329:447-449. http://dx.doi.org/10.1038/329447a0

Klein, L., B. Kyewski, P.M. Allen, and K.A. Hogquist. 2014. Positive and negative selection of the $\mathrm{T}$ cell repertoire: What thymocytes see (and don't see). Nat. Rev. Immunol. 14:377-391. http://dx.doi.org/10.1038 $/$ nri3667

Kristiansen, O.P., A.E. Karlsen, Z.M. Larsen, J. Johannesen, F. Pociot, and T. Mandrup-Poulsen. Danish IDDM Epidemiology and Genetics Group and Danish Study Group of IDDM in Childhood. 2004. Identification of a type 1 diabetes-associated CD4 promoter haplotype with high constitutive activity. Scand. J. Immunol. 59:582-591. http://dx.doi.org /10.1111/j.1365-3083.2004.01444.x

Krogsgaard, M., and M.M. Davis. 2005. How T cells 'see' antigen. Nat. Immunol. 6:239-245. http://dx.doi.org/10.1038/ni1173

Li, L.P., J.C. Lampert, X. Chen, C. Leitao, J. Popović, W. Müller, and T. Blankenstein. 2010. Transgenic mice with a diverse human $\mathrm{T}$ cell antigen receptor repertoire. Nat. Med. 16:1029-1034. http://dx.doi.org/10 $.1038 / \mathrm{nm} .2197$

Marrack, P., J.P. Scott-Browne, S. Dai, L. Gapin, and J.W. Kappler. 2008. Evolutionarily conserved amino acids that control TCRMHC interaction. Annu. Rev. Immunol. 26:171-203. http://dx.doi.org/10.1146 /annurev.immunol.26.021607.090421

Marten, N.W., S.A. Stohlman, W. Smith-Begolka, S.D. Miller, E. Dimacali, Q. Yao, S. Stohl, J. Goverman, and C.C. Bergmann. 1999. Selection of CD8 $\mathrm{T}$ cells with highly focused specificity during viral persistence in the central nervous system. J. Immunol. 162:3905-3914.

McDonald, B.D., J.J. Bunker, S.A. Erickson, M. Oh-Hora, A. Bendelac, B.D Mcdonald, J.J. Bunker, S.A. Erickson, M. Oh-hora, and A. Bendelac. 2015. Crossreactive $\alpha \beta$ T Cell receptors are the predominant targets of thymocyte negative selection. Immunity. 43:859-869. http://dx.doi.org /10.1016/j.immuni.2015.09.009

Merkenschlager, M., D. Graf, M. Lovatt, U. Bommhardt, R. Zamoyska, and A.G. Fisher. 1997. How many thymocytes audition for selection? J. Exp. Med. 186:1149-1158. http://dx.doi.org/10.1084/jem.186.7.1149 
Nazarov, V.I., M.V. Pogorelyy, E.A. Komech, I.V. Zvyagin, D.A. Bolotin, M. Shugay, D.M. Chudakov,Y.B. Lebedev, and I.Z. Mamedov. 2015. tcR: an $\mathrm{R}$ package for $\mathrm{T}$ cell receptor repertoire advanced data analysis. $B M C$ Bioinformatics. 16:175. http://dx.doi.org/10.1186/s12859-015-0613-1

Nikolich-Žugich,J., M.K. Slifka, and I. Messaoudi. 2004. The many important facets of T-cell repertoire diversity. Nat. Rev. Immunol. 4:123-132. http:// dx.doi.org/10.1038/nri1292

Robins, H.S., P.V.Campregher, S.K. Srivastava,A.Wacher, C.J.Turtle, O. Kahsai, S.R. Riddell, E.H. Warren, and C.S. Carlson. 2009. Comprehensive assessment of T-cell receptor $\beta$-chain diversity in $\alpha \beta \mathrm{T}$ cells. Blood. 114:4099-4107. http://dx.doi.org/10.1182/blood-2009-04-217604

Robins, H.S., S.K. Srivastava, P.V. Campregher, C.J. Turtle, J. Andriesen, S.R. Riddell, C.S. Carlson, and E.H. Warren. 2010. Overlap and effective size of the human $\mathrm{CD}^{+} \mathrm{T}$ cell receptor repertoire. Sci. Transl. Med. 2:47ra64. http://dx.doi.org/10.1126/scitranslmed.3001442

Robinson, J., M.J. Waller, P. Parham, N. de Groot, R. Bontrop, L.J. Kennedy, P. Stoehr, and S.G.E. Marsh. 2003. IMGT/HLA and IMGT/MHC: Sequence databases for the study of the major histocompatibility complex. Nucleic Acids Res. 31:311-314. http://dx.doi.org/10.1093/nar /gkg070

Rossjohn, J., S. Gras, J.J. Miles, S.J. Turner, D.I. Godfrey, and J. McCluskey. 2015. T cell antigen receptor recognition of antigen-presenting molecules. Annu. Rev. Immunol. 33:169-200. http://dx.doi.org/10.1146 /annurev-immunol-032414-112334

Rubelt, F., C.R. Bolen, H.M. McGuire, J.A. Vander Heiden, D. GadalaMaria, M. Levin, G.M. Euskirchen, M.R. Mamedov, G.E. Swan, C.L. Dekker, et al. 2016. Individual heritable differences result in unique cell lymphocyte receptor repertoires of naïve and antigen-experienced cells. Nat. Commun. 7:11112. http://dx.doi.org/10.1038/ncomms11112

Scott-Browne, J.P., J. White, J.W. Kappler, L. Gapin, and P. Marrack. 2009 Germline-encoded amino acids in the $\alpha \beta$ T-cell receptor control thymic selection. Nature. 458:1043-1046. http://dx.doi.org/10.1038/ nature 07812

Scott-Browne, J.P., F. Crawford, M.H.Young, J.W. Kappler, P. Marrack, and L. Gapin. 2011. Evolutionarily conserved features contribute to $\alpha \beta \mathrm{T}$ cell receptor specificity. Immunity. 35:526-535. http://dx.doi.org/10.1016/j .immuni.2011.09.005

Sethi, D.K., D.A. Schubert, A.K. Anders, A. Heroux, D.A. Bonsor, C.P Thomas, E.J. Sundberg, J. Pyrdol, and K.W. Wucherpfennig. 2011. A highly tilted binding mode by a self-reactive $\mathrm{T}$ cell receptor results in altered engagement of peptide and MHC. J. Exp. Med. 208:91-102. http ://dx.doi.org/10.1084/jem.20100725

Sharon, E., L.V. Sibener, A. Battle, H.B. Fraser, K.C. Garcia, and J.K. Pritchard 2016. Genetic variation in MHC proteins is associated with $\mathrm{T}$ cell receptor expression biases. Nat. Genet. 48:995-1002. http://dx.doi.org $/ 10.1038 /$ ng. 3625
Suchin, E.J., P.B. Langmuir, E. Palmer, M.H. Sayegh, A.D. Wells, and L.A. Turka. 2001. Quantifying the frequency of alloreactive $\mathrm{T}$ cells in vivo: New answers to an old question. J. Immunol. 166:973-981. http://dx.doi .org/10.4049/jimmunol.166.2.973

Tikhonova, A.N., F.Van Laethem, K. Hanada, J. Lu, L.A. Pobezinsky, C. Hong, T.I. Guinter, S.K. Jeurling, G. Bernhardt, J.-H. Park, et al. 2012. $\alpha \beta$ T cell receptors that do not undergo major histocompatibility complexspecific thymic selection possess antibody-like recognition specificities. Immunity. 36:79-91. http://dx.doi.org/10.1016/j.immuni.2011.11.013

Tynan, F.E., S.R. Burrows, A.M. Buckle, C.S. Clements, N.A. Borg, J.J. Miles, T. Beddoe, J.C. Whisstock, M.C. Wilce, S.L. Silins, et al. 2005. T cell receptor recognition of a 'super-bulged' major histocompatibility complex class I-bound peptide. Nat. Immunol. 6:1114-1122. http://dx doi.org/10.1038/ni1257

Van Laethem, F., A.N. Tikhonova, L.A. Pobezinsky, X. Tai, M.Y. Kimura, C. Le Saout, T.I. Guinter, A. Adams, S.O. Sharrow, G. Bernhardt, et al. 2013. Lck availability during thymic selection determines the recognition specificity of the T cell repertoire. Cell. 154:1326-1341. http://dx.doi .org/10.1016/j.cell.2013.08.009

Vrisekoop, N., J.P. Monteiro, J.N. Mandl, R.N. Germain, N. Vrisekoop, J.P. Monteiro, J.N. Mandl, and R.N. Germain. 2014. Revisiting thymic positive selection and the mature $\mathrm{T}$ cell repertoire for antigen. Immunity. 41:181-190. http://dx.doi.org/10.1016/j.immuni.2014.07.007

Waterston, R.H., K. Lindblad-Toh, E. Birney, J. Rogers, J.F. Abril, P. Agarwal, R. Agarwala, R. Ainscough, M. Alexandersson, P. An, et al. Mouse Genome Sequencing Consortium. 2002. Initial sequencing and comparative analysis of the mouse genome. Nature. 420:520-562. http:// dx.doi.org/10.1038/nature01262

Xing, Y., and K.A. Hogquist. 2014. Isolation, identification, and purification of murine thymic epithelial cells. J. Vis. Exp. (90):e51780. http://dx.doi .org/10.3791/51780

Yassai, M., K. Ammon, J. Goverman, P. Marrack, Y. Naumov, and J. Gorski. 2002. A molecular marker for thymocyte-positive selection: selection of CD4 single-positive thymocytes with shorter TCRB CDR3 during T cell development. J. Immunol. 168:3801-3807. http://dx.doi.org/10 .4049/jimmunol.168.8.3801

Zerrahn, J., W. Held, and D.H. Raulet. 1997. The MHC reactivity of the T cell repertoire prior to positive and negative selection. Cell. 88:627-636. http://dx.doi.org/10.1016/S0092-8674(00)81905-4

Zvyagin, I.V., M.V. Pogorelyy, M.E. Ivanova, E.A. Komech, M. Shugay, D.A. Bolotin, A.A. Shelenkov, A.A. Kurnosov, D.B. Staroverov, D.M. Chudakov, et al. 2014. Distinctive properties of identical twins' TCR repertoires revealed by high-throughput sequencing. Proc. Natl. Acad. Sci. USA. 111:5980-5985. http://dx.doi.org/10.1073/pnas.1319389111 